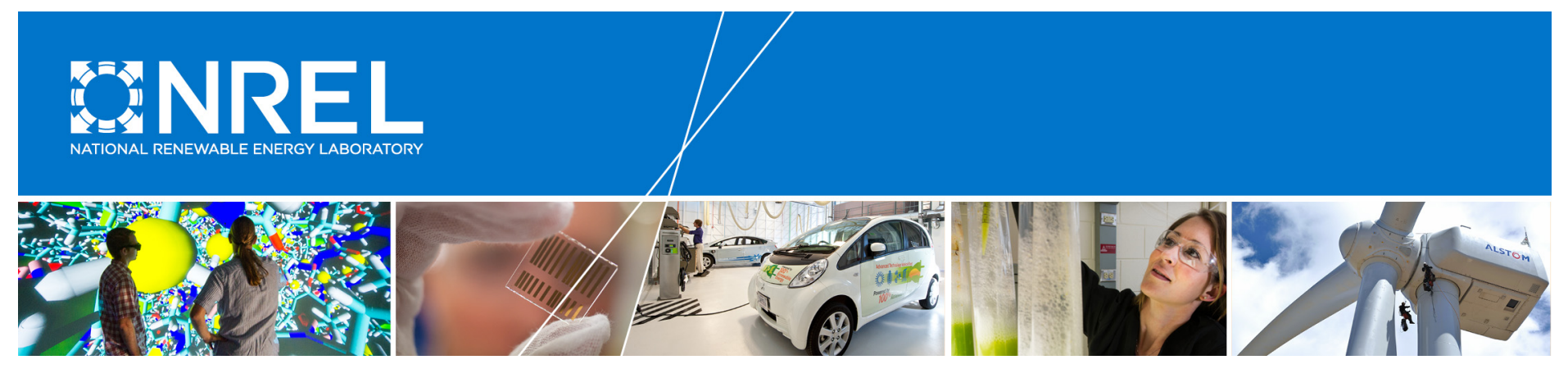

\title{
Estimated Bounds and Important Factors for Fuel Use and Consumer Costs of Connected and Automated Vehicles
}

T.S. Stephens

Argonne National Laboratory

J. Gonder and Y. Chen

National Renewable Energy Laboratory

Z. Lin and C. Liu

Oak Ridge National Laboratory

D. Gohlke

U.S. Department of Energy

NREL is a national laboratory of the U.S. Department of Energy Office of Energy Efficiency \& Renewable Energy Operated by the Alliance for Sustainable Energy, LLC

This report is available at no cost from the National Renewable Energy Laboratory (NREL) at www.nrel.gov/publications.

Technical Report

NREL/TP-5400-67216

November 2016

Contract No. DE-AC36-08GO28308 


\section{Estimated Bounds and Important Factors for Fuel Use and Consumer Costs of Connected and Automated Vehicles}

T.S. Stephens

Argonne National Laboratory

J. Gonder and Y. Chen

National Renewable Energy Laboratory

Z. Lin and C. Liu

Oak Ridge National Laboratory

D. Gohlke

U.S. Department of Energy
NREL is a national laboratory of the U.S. Department of Energy Office of Energy Efficiency \& Renewable Energy Operated by the Alliance for Sustainable Energy, LLC

This report is available at no cost from the National Renewable Energy Laboratory (NREL) at www.nrel.gov/publications.

\section{Technical Report}

NREL/TP-5400-67216

November 2016

Contract No. DE-AC36-08GO28308
National Renewable Energy Laboratory 5013 Denver West Parkway

Golden, CO 80401

303-275-3000 • www.nrel.gov 


\section{NOTICE}

This report was prepared as an account of work sponsored by an agency of the United States government. Neither the United States government nor any agency thereof, nor any of their employees, makes any warranty, express or implied, or assumes any legal liability or responsibility for the accuracy, completeness, or usefulness of any information, apparatus, product, or process disclosed, or represents that its use would not infringe privately owned rights. Reference herein to any specific commercial product, process, or service by trade name, trademark, manufacturer, or otherwise does not necessarily constitute or imply its endorsement, recommendation, or favoring by the United States government or any agency thereof. The views and opinions of authors expressed herein do not necessarily state or reflect those of the United States government or any agency thereof.

This report is available at no cost from the National Renewable Energy Laboratory (NREL) at www.nrel.gov/publications.

Available electronically at SciTech Connect http:/www.osti.gov/scitech

Available for a processing fee to U.S. Department of Energy and its contractors, in paper, from:

U.S. Department of Energy

Office of Scientific and Technical Information

P.O. Box 62

Oak Ridge, TN 37831-0062

OSTI http://www.osti.gov

Phone: 865.576.8401

Fax: 865.576.5728

Email: reports@osti.gov

Available for sale to the public, in paper, from:

U.S. Department of Commerce

National Technical Information Service

5301 Shawnee Road

Alexandria, VA 22312

NTIS http://www.ntis.gov

Phone: 800.553 .6847 or 703.605 .6000

Fax: 703.605.6900

Email: orders@ntis.gov 


\section{Acknowledgments}

Funding for this study was provided by the Vehicle Technologies Office within the U.S. Department of Energy's Office of Energy Efficiency and Renewable Energy. The authors would particularly like to thank Rachael Nealer and Jacob Ward for their support and guidance. Additional thanks goes to Josh Auld, Vadim Sokolov and Joann Zhou from ANL, to Al Hicks, Stephanie Price and Julia Thomas from NREL, and to James Li from ORNL for all of their help and input. 


\section{List of Acronyms}

ANL

ACAS

CAV

FHWA

I2V

LB

LDV

NHTS

NREL

OEM

ORNL

PMT

TTI

UB

V2I

VMT
Argonne National Laboratory

Automotive rear-end Collision Avoidance System connected and automated vehicle

Federal Highway Administration

infrastructure-to-vehicle

lower bound

light-duty vehicle

National Household Travel Survey

National Renewable Energy Laboratory

original equipment manufacturer

Oak Ridge National Laboratory

person miles traveled

Texas A\&M Transportation Institute

upper bound

vehicle-to-infrastructure

vehicle miles traveled 


\section{Executive Summary}

This report estimates ranges of potential effects of connected and automated vehicle (CAV) technologies on vehicle miles traveled (VMT), vehicle fuel efficiency, and costs to consumers. Analysis combining the VMT and efficiency effects under assumed high CAV market penetration produces national-level impact ranges for fuel use and, by extension, greenhouse gas emissions, since fuel switching (i.e., from gasoline to alternative fuels) is not considered. The analysis of CAV costs to consumers draws upon the potential changes to VMT and vehicle efficiency, plus available data and assumptions on CAV technology cost projections. Figure ES1 illustrates the overall structure of the analysis to determine ranges of potential CAV effects on VMT and vehicle efficiency, and combine these to evaluate impact ranges for national light-duty vehicle (LDV) fuel use and for CAV technology costs to consumers.

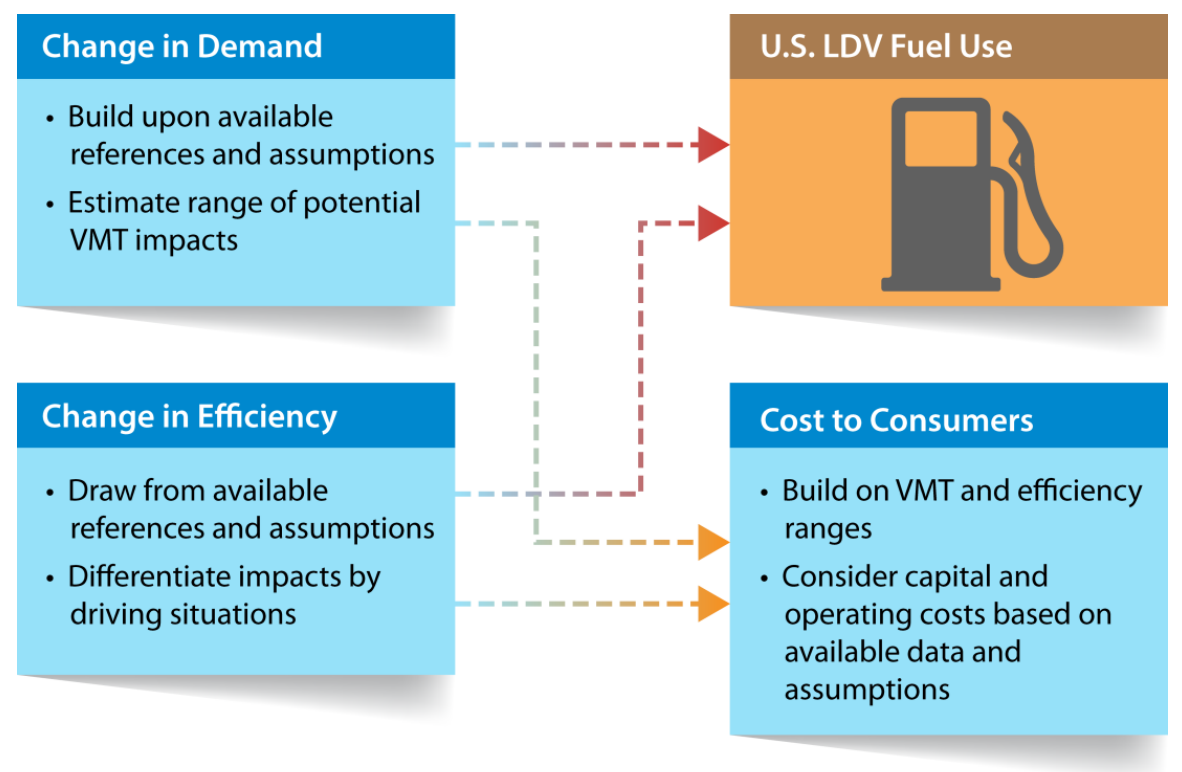

Figure ES-1. Visualization of the analysis process for the report

The travel demand and efficiency impact range estimates draw upon results from previous studies that evaluated various CAV technology effects on conventional vehicle operation. The VMT impact calculations include vehicle occupancy assumptions to translate between person miles traveled (PMT) and VMT. The efficiency calculations rely on literature-reported values for different CAV feature impacts on fuel consumption rates (e.g., due to vehicle-to-infrastructure communication / coordination, vehicle platooning, etc.), and also include a first-order disaggregation of each feature's impact in different driving situations (i.e., city vs. highway driving and travel at peak vs. off-peak times). The relative impacts are then weighted by the amount of driving that takes place in those different situations.

The analysis combines the ranges of CAV technology effects on VMT and fuel consumption rates over the total U.S. LDV stock. These calculations produce lower- and upper-bound estimates of potential total U.S. LDV fuel use (and greenhouse gas emission) impacts for three CAV scenarios relative to a present-day base scenario. The present-day base scenario represents fuel use by the current U.S. on-road light-duty vehicle fleet, consisting of essentially all 
conventional, gasoline-powered light duty vehicles. The three CAV scenarios considered include:

- Partial: Partial automation with some connectivity

- Full-No Rideshare: Full automation with high connectivity without ridesharing

- Full-With Rideshare: Full automation with high connectivity with ridesharing.

Here, partial automation was assumed to include technologies such as driver assistance that still require an attentive driver to control the vehicle, corresponding to SAE levels 1 or 2 (SAE, 2016), with limited connectivity. Full automation was assumed to correspond to SAE Levels 4 and 5, allowing vehicle operation without an attentive driver (or even without a person in the vehicle), and with connectivity permitting communication between travelers, vehicles, traffic control devices, and traffic control centers. Ridesharing refers to a net increase in vehicle occupancy resulting from two or more people riding together in a vehicle during some or all of their travel.

The upper bound estimates for each scenario assume maximally energy increasing combinations of CAV effects on VMT and vehicle efficiency (i.e., many more miles traveled with little or no fuel economy gains), whereas the lower bound estimates assume the reverse (i.e., minimal increases in VMT combined with more aggressive vehicle efficiency improvements). The results (summarized in Figure ES-2) illustrate wide separation between the scenarios' upper and lower bounds on U.S. LDV fuel use, reflecting the large uncertainties in CAVs' impacts on both vehicle fuel consumption rates and VMT. The upper bound for the Full-No Rideshare scenario represents the highest increasing fuel use case with triple the annual fuel use of the base scenario. The lower bound of the "Full-With Rideshare" scenario represents the lowest decreasing fuel use case with less than $40 \%$ of the base scenario's fuel use ${ }^{1}$. In contrast, the partial automation scenario shows a much more modest range of impacts, on the order of $\pm 10 \%$ for the upper and lower bounds relative to the base scenario.

The figure also highlights the most important factors influencing the upper and lower bounds on fuel use. For the upper bound cases, large VMT changes due to easier travel (faster travel and reduced travel time cost) serve as the largest driver on increasing fuel consumption, with empty travel by driverless CAVs and increased fuel consumption per mile due to high-speed travel representing the next most influential factors. In the lower bound scenarios, decreased fuel use is largely due to aggressive vehicle and powertrain downsizing, combined with smoother driving and only modest VMT increases (which can be further offset by ridesharing).

\footnotetext{
${ }^{1}$ This analysis only considers CAVs with conventional gasoline-powered drivetrains, but a scenario including synergistic interactions of CAVs technologies and electric drive could result in an even lower bound than that reported in this study. Some early studies have suggested that the combination of CAVs with vehicle electrification could achieve lower bound fuel savings in excess of 90\% (Brown et al. 2014, Greenblatt and Saxena 2015).
} 


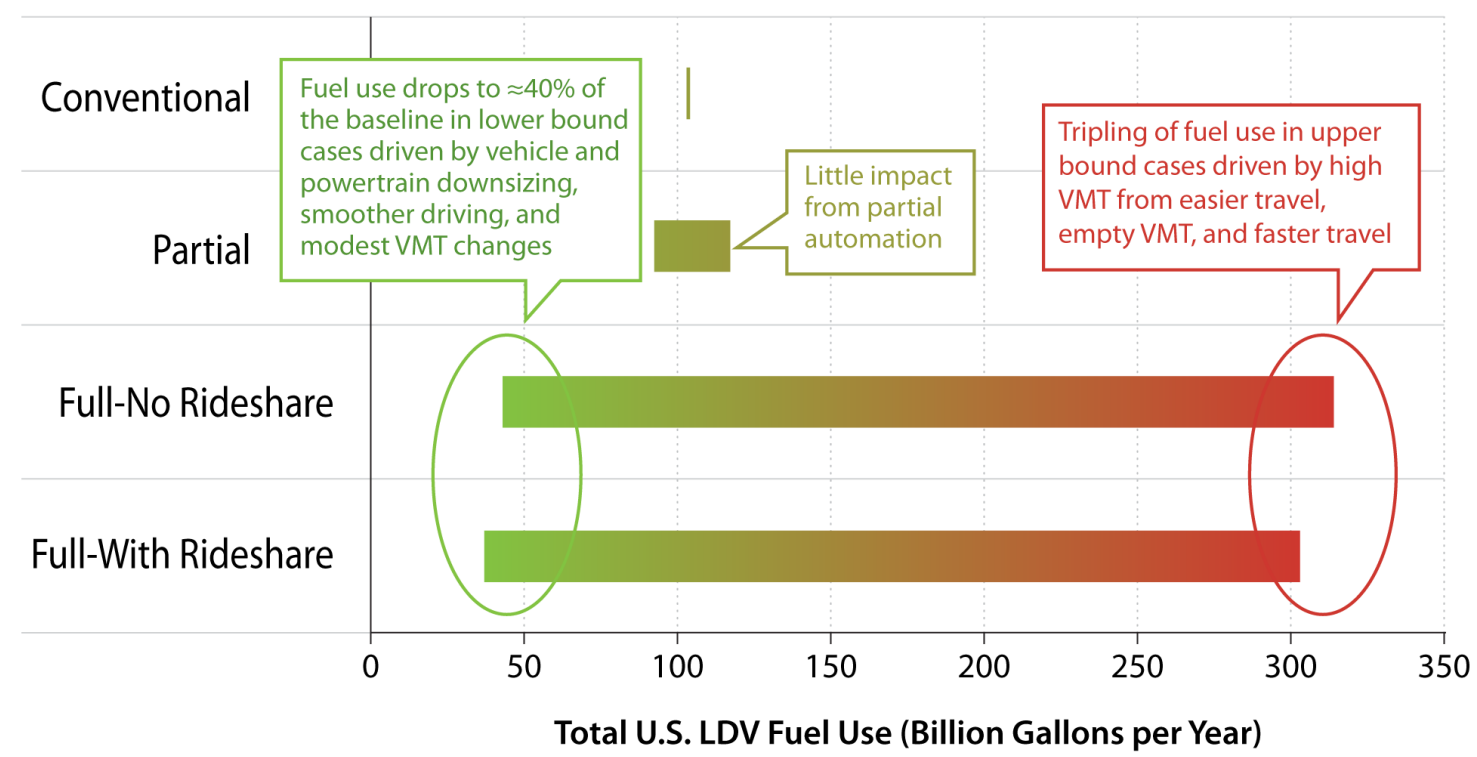

Figure ES-2. Estimated bounds on total U.S. LDV fuel use per year under the base (Conventional) and three CAV scenarios, based on the study's synthesis approach from CAV feature impact ranges reported in existing literature

CAV ownership and operating costs reviewed include vehicle purchase price, insurance, value of travel time, and other various costs that may be impacted by CAV technology adoption. Compared to the conventional baseline, most scenarios show substantial decreases in costs to consumers. The lower end assumptions in the "Full-With Rideshare" scenario generate the largest estimated cost reduction (roughly $60 \%$ relative to the base scenario on a cost per passenger mile basis, when accounting for the cost of travel time). The upper-end assumptions for the Partial automation scenario produce the only cost increasing case relative to the baseline. For this case assumptions of higher vehicle purchase and repair costs together with little or no benefits with respect to insurance and travel time costs result in a net 3\%-4\% cost increase relative to the baseline. The most significant (and most uncertain) cost component is consumers' perceived travel time cost (which significantly impacts potential VMT changes).

The potential factors affecting future CAV use, energy consumption, and costs and the nature of their influence are highly uncertain. This report identifies and highlights possible key sources of uncertainty and suggests areas of research to address them. Noteworthy areas for further investigation include the degree to which different CAV efficiency features interact and result in non-additive fuel saving benefits, especially in advanced powertrain vehicles (e.g., hybrid electric and plug-in battery electric vehicles). 


\section{Table of Contents}

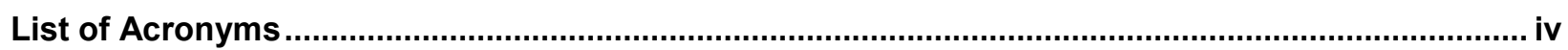

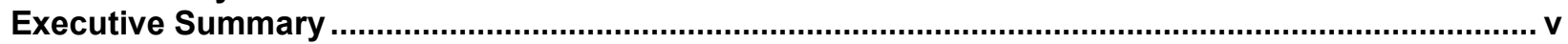

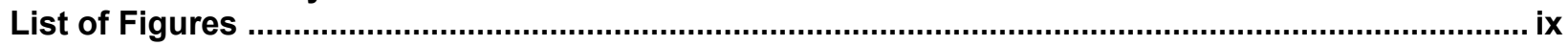

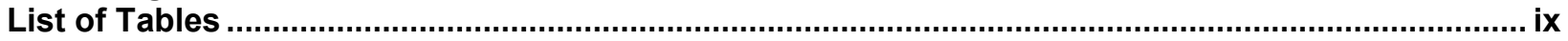

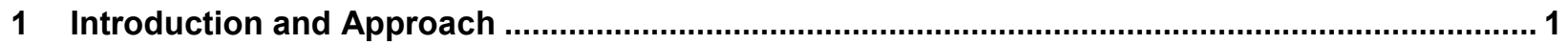

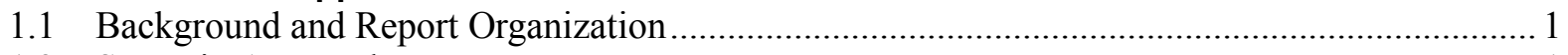

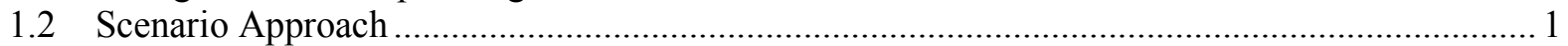

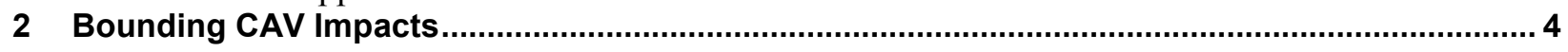

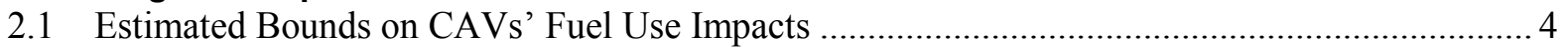

2.2 Estimated Bounds on CAVs' Costs to Consumers .................................................................. 8

3 Details on Methodology and on Input Assumptions Extracted from Literature .........................11

3.1 Literature and Methodology Discussion for Potential CAV Impacts on Fuel Use .................... 11

3.1.1 Literature on Travel Demand Impact of CAV Technologies....................................... 11

3.1.2 Literature on Fuel Efficiency Impact of CAV Technologies ...................................... 18

3.1.3 Methodology to Aggregate National Consumption Impacts.......................................2 24

3.2 Literature and Methodology Discussion for Potential CAV Impacts on Consumer Costs ......... 26

4 Most Important Factors and Uncertainties for CAVs Impact Estimates .....................................32

4.1 Most Important Factors Contributing to Changes in Fuel Use.............................................. 32

4.2 Important Uncertainties, Knowledge Gaps, and Limitations of Current Methods..................... 35

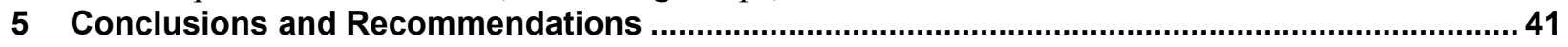

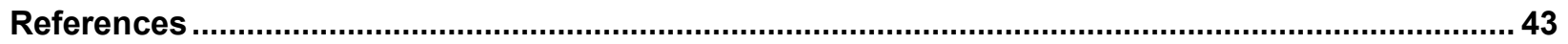




\section{List of Figures}

Figure ES-1. Visualization of the analysis process for the report.......................................................

Figure ES-2. Estimated bounds on total U.S. LDV fuel use per year under the base (Conventional) and three CAV scenarios, based on the study's synthesis approach from CAV feature impact ranges reported in existing literature ............................................................................. vii

Figure 1. Visualization of the analysis process for each scenario.................................................... 2 Figure 2. Visualization of the analysis process to estimate upper and lower bound national LDV fuel use impacts for each of the CAV scenarios, based on combining the ranges of potential CAV

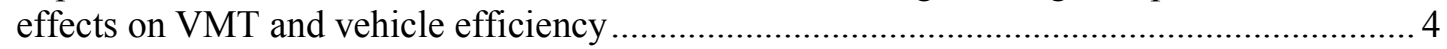

Figure 3. Potential national LDV VMT under the "Conventional" and CAV scenarios ............................... 5 Figure 4. Estimated bounds on vehicle fuel consumption rate (gallons of gasoline per 100 miles of driving) for each of the scenarios....................................................................................... 7

Figure 5. Upper bound (UB) and lower bound (LB) estimates on total U.S. LDV fuel use per year under each CAV scenario compared with the Conventional base scenario .................................... 7

Figure 6. Visualization of the analysis process to estimate bounds on costs to consumers for each of the

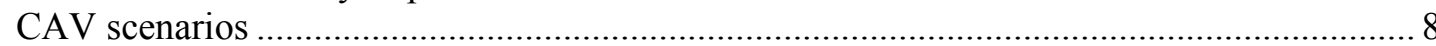

Figure 7. Estimated bounds on consumer cost components under the Conventional and selected CAV

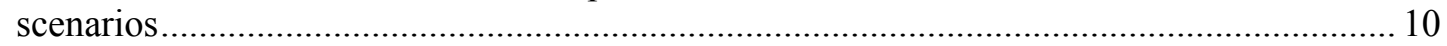

Figure 8. Vehicle-level fuel consumption per mile impact under different automation technologies........ 26

Figure 9. OEM pricing of driver assistance packages..................................................................... 28

Figure 10. Influence of each demand and vehicle efficiency effect on total fuel use, for the "Full-With Rideshare-UB" case shown as percentages of total baseline fuel consumption .................... 34

Figure 11. Influence of each demand and vehicle efficiency effect on total fuel use, for the "Full-With Rideshare-LB" case shown as percentages of total baseline fuel consumption..................... 35

\section{List of Tables}

Table 1. Major Assumptions Defining the Scenarios and Bounds for the Light-Duty CAV Energy Impact

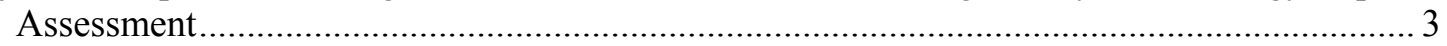

Table 2. Potential VMT, PMT, and Average Vehicle Occupancy in the Four Scenarios Considered ......... 5 Table 3. Percentage of VMT and Fuel Economy Assumed for a Baseline, Conventional Vehicle by Road

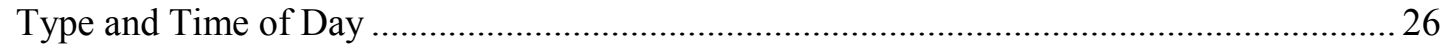

Table 4. 2015 Honda Accord Five-Year Ownership Cost ....................................................................... 28

Table 5. Assumptions about the Important Factors Influencing Lower and Upper Bounds of the Potential Energy Impacts of Advanced CAV Technologies ............................................................... 33

Table 6. Key Uncertainties in Estimating the Potential Impacts of Advanced CAV Technologies on

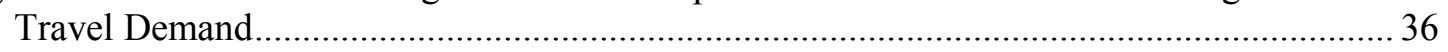

Table 7. Key Uncertainties in Estimating the Potential Adoption Levels of Advanced CAV

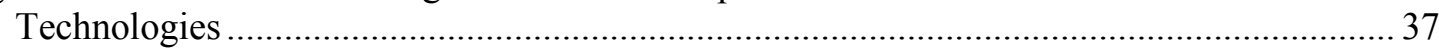

Table 8. Key Uncertainties in Estimating the Potential Impacts of Advanced CAV Technologies on

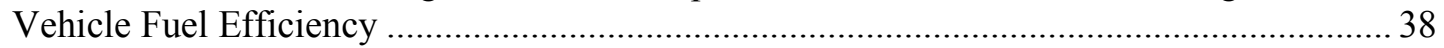

Table 9. Key Uncertainties in Estimating the Potential Impacts of Advanced CAV Technologies on

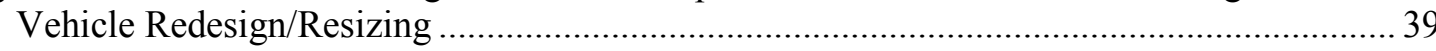

Table 10. Key Uncertainties in Estimating the Potential Energy Impacts of Heavy-Duty CAV Technologies 


\section{Introduction and Approach}

\subsection{Background and Report Organization}

The rapid advancement of connected and automated vehicle (CAV) technologies may disrupt vehicle use, ownership, and design, resulting in large changes in energy consumption, use of alternative transportation modes, and development and deployment of efficiency-improving vehicle technologies. To help identify analysis and research needs related to CAVs, this report:

- Reviews recent literature related to CAVs

- Provides a framework that synthesizes analysis and simulation case studies of potential CAV deployment scenarios

- Identifies key knowledge gaps and uncertainties for assessing CAV energy impacts, emphasizing future research and analysis priorities to better understand these impacts.

The remainder of Section 1 describes the scenario-based approach used by this study to examine CAV technology impacts. Section 2 estimates lower and upper bounds on the long-term impacts of CAVs for light-duty vehicles (LDVs) with a focus on energy impacts in Section 2.1 and on consumer costs in Section 2.2. Section 3 provides details on the analysis methodology and literature-extracted input assumptions that supported the Section 2 findings. Section 4 highlights the major factors contributing to the ranges of potential CAV impacts identified in Section 2, and discusses key data gaps and uncertainties identified as priority areas for future research to address. Section 5 summarizes the report's findings and conclusions.

\subsection{Scenario Approach}

Figure 1 illustrates the overall structure for the analysis of each of the scenarios in this report. This includes determining ranges of potential CAV effects on vehicle miles traveled (VMT) and vehicle efficiency, and combining these to evaluate impact ranges for national light-duty vehicle (LDV) fuel use and for CAV technology costs to consumers. The future adoption level of CAVs is an important consideration for such an impact assessment, but is highly uncertain. To bound potential ranges of impacts, this assessment assumes complete CAV adoption under several distinct scenarios. These include a baseline scenario to represent fuel use by the current U.S. LDV fleet, and three CAV scenarios differentiated by automation and connectivity level and assumed level of ridesharing. 


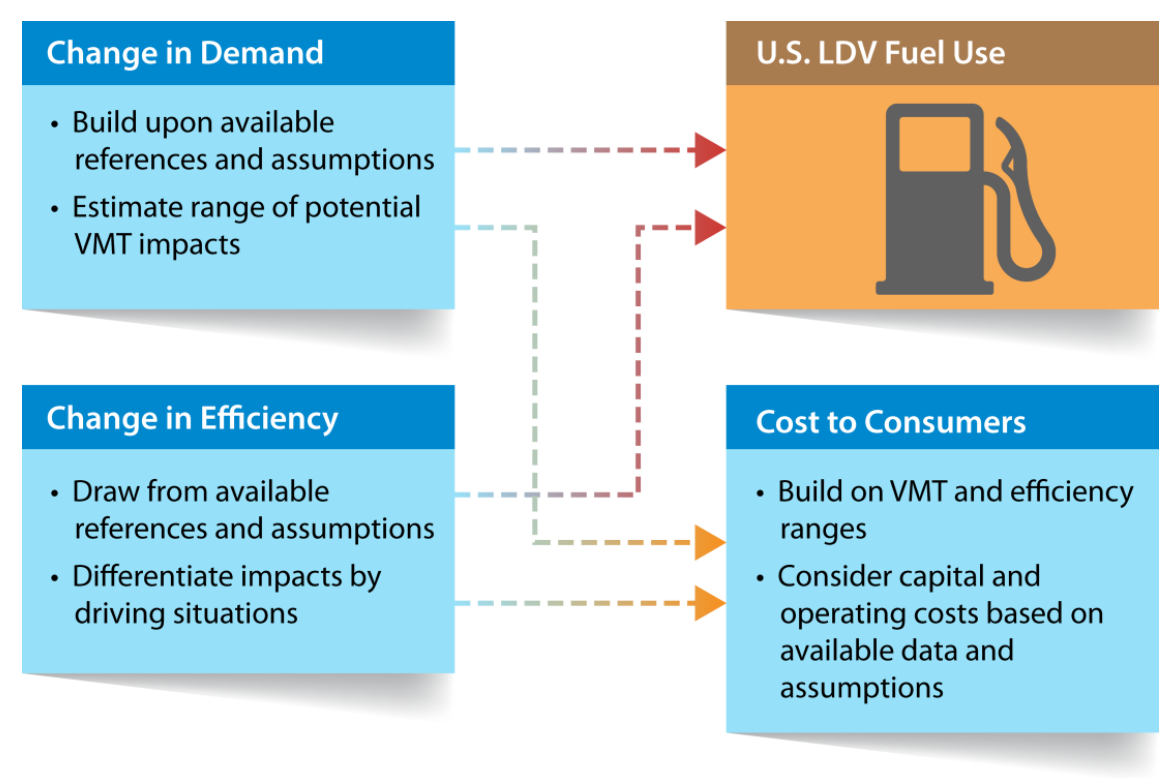

Figure 1. Visualization of the analysis process for each scenario

The automation level distinctions within the CAV scenarios include partial automation, such as driver assistance technologies that still require an attentive driver to control the vehicle, and full automation, including driverless vehicles. The fully connected and automated scenarios are further subdivided into two: with and without ridesharing. The four selected scenarios (including the baseline) are named to indicate the assumed level of automation and whether or not ridesharing is included, as follows:

1. "Conventional," the base case of current conventional (without automation or connectivity) privately owned vehicles

2. "Partial," partially automated and connected, privately owned vehicles

3. "Full-No Rideshare," fully automated and connected vehicles with no ridesharing

4. "Full-With Rideshare," fully automated and connected vehicles with ridesharing.

Here, partial automation is assumed to include technologies such as driver assistance that still require an attentive driver to control the vehicle, corresponding to SAE levels 1 or 2 (SAE, 2016), with limited connectivity. Full automation is assumed to correspond to SAE Levels 4 and 5 , allowing vehicle operation without an attentive driver (or even without a person in the vehicle), and with connectivity permitting communication between travelers, vehicles, traffic control devices, and traffic control centers. Ridesharing refers to a net increase in vehicle occupancy such as might occur with increased communication between travelers and better information about the potential to coordinate travel. Although it is recognized that different vehicle ownership models, such as car sharing versus private ownership, may be become more widespread with increasing vehicle automation and connectivity, insufficient information on the energy impacts of such ownership differences in combination with automation and connectivity was found in reviewing previous work, so this factor is not evaluated explicitly. Though this report does not draw a distinction between potential energy impacts that could arise for private versus shared CAVs, an argument can be made that the largest potential impacts of vehicle resizing and ridesharing may be most likely realized under a fleet ownership model. 
To assess the upper and lower bounds on fuel use for each scenario, the analysis combines the respective highest and lowest anticipated values of individual CAV's feature effects on fuel efficiency and VMT. Section 3 provides detailed descriptions on the source for each of these high and low input assumptions. The combinations of these assumed levels in each of the five scenarios are shown in Table 1.

Table 1. Major Assumptions Defining the Scenarios and Bounds for the Light-Duty CAV Energy Impact Assessment

\begin{tabular}{cccccc}
\hline \multirow{2}{*}{ Scenario } & $\begin{array}{l}\text { Automation and } \\
\text { Connectivity Level }\end{array}$ & Ridesharing & $\begin{array}{l}\text { Upper or } \\
\text { Lower Bound }\end{array}$ & $\begin{array}{l}\text { Efficiency } \\
\text { Improvement }\end{array}$ & $\begin{array}{l}\text { VMT } \\
\text { Increase }\end{array}$ \\
\hline Conventional & None & No & N/A & N/A & N/A \\
Partial & Partial & No & Upper & Low & High \\
\hline \multirow{2}{*}{ Full-No Rideshare } & Full & No & Lower & High & Low \\
\hline \multirow{2}{*}{ Full-With Rideshare } & Full & Yoner & Low & High \\
\hline
\end{tabular}




\section{Bounding CAV Impacts}

\subsection{Estimated Bounds on CAVs' Fuel Use Impacts}

This section describes the analysis process to estimate bounds on national LDV fuel use for each of the CAV scenarios. Figure 2 illustrates the structure of that analysis, which combines ranges of CAV technology travel demand and efficiency impacts within each scenario to calculate the upper and lower bound fuel use impacts.

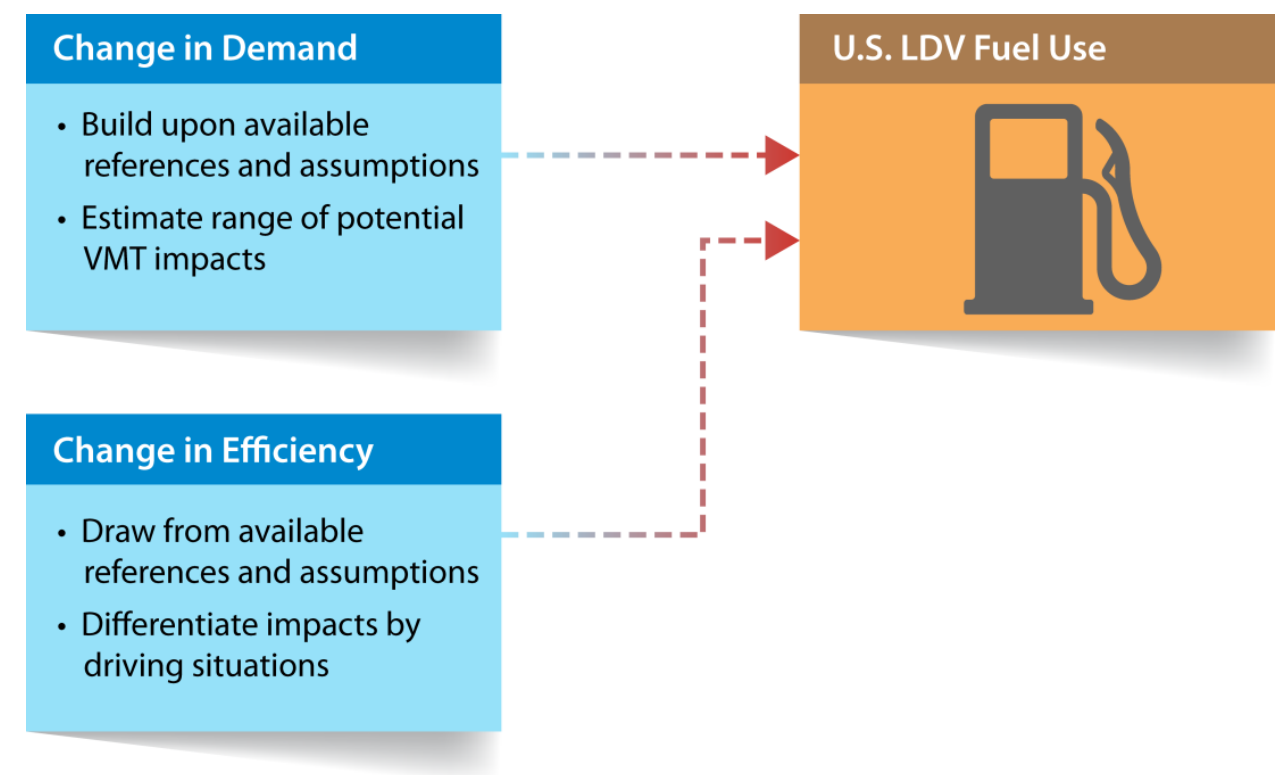

Figure 2. Visualization of the analysis process to estimate upper and lower bound national LDV fuel use impacts for each of the CAV scenarios, based on combining the ranges of potential CAV effects on VMT and vehicle efficiency

Previous work (detailed in Section 3.1.1) has identified the following categories of potential CAV technology effects on travel demand and the resulting VMT:

- Less hunting for parking

- More travel due to it becoming easier (from faster travel and decreased cost of travel)

- Increased travel by populations whose transportation needs are currently underserved

- Mode shift from walking, transit and regional air

- Increase in ridesharing

- Increased empty miles traveled by automated vehicles.

For each category, estimated magnitudes of potential CAVs influences are taken from the previous studies and the highest and lowest estimates provide the upper and lower bounds, respectively. The assumptions and methods to combine estimated VMT changes from literature are further discussed in Section 3.1.1, and the resulting large ranges of potential VMT changes for each CAVs scenario are shown in Figure 3. The upper bound is labeled "UB," and the lower bound "LB" in the figure. Except for less hunting for parking and increased ridesharing, the factors influencing VMT are expected to increase VMT. The largest potential increase is 
associated with easier travel (due to faster travel and reduced travel-time cost). As is evident from the wide differences between upper and lower bounds on VMT, there is enormous uncertainty in the effect of CAVs on travel demand for the full automation scenarios.

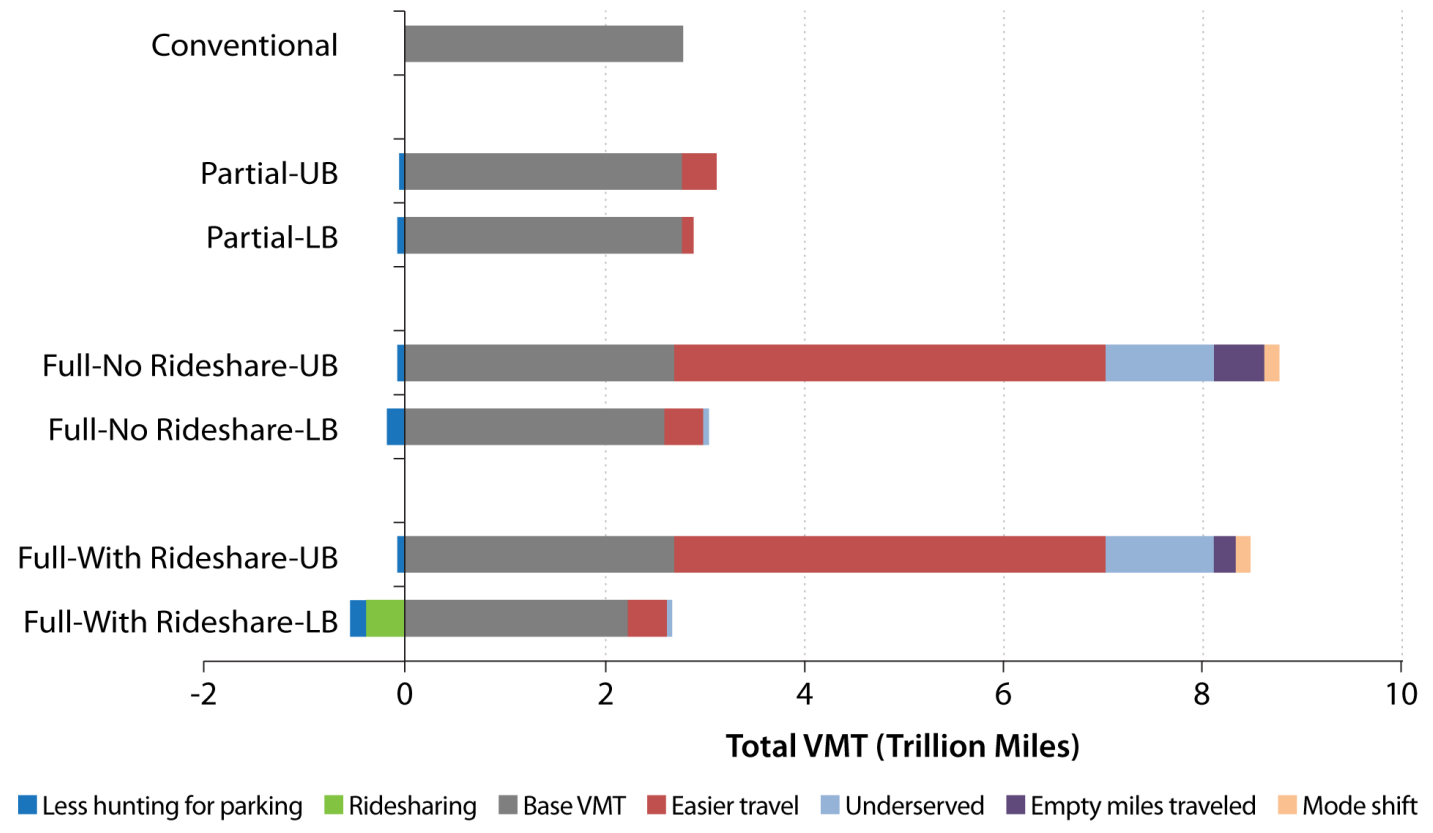

Figure 3. Potential national LDV VMT under the "Conventional" and CAV scenarios

From estimated VMT and vehicle occupancy, person miles traveled (PMT) are also tabulated for each scenario (Table 2).

Table 2. Potential VMT, PMT, and Average Vehicle Occupancy in the Four Scenarios Considered

\begin{tabular}{llll}
\hline Scenario & $\begin{array}{l}\text { Total VMT } \\
\text { (Trillion } \\
\text { mi/yr) }\end{array}$ & $\begin{array}{l}\text { Total PMT } \\
\text { (Trillion } \\
\text { mi/yr) }\end{array}$ & $\begin{array}{l}\text { Average } \\
\text { Occupancy }\end{array}$ \\
\hline Conventional & 2.8 & 4.7 & 1.7 \\
Partial & $2.8-3.1$ & $4.7-5.2$ & 1.7 \\
Full-No Rideshare & $3.1-8.8$ & $5.1-13.8$ & $1.6-1.7$ \\
Full-With Rideshare & $2.7-8.5$ & $5.1-13.8$ & $1.6-1.9$ \\
\hline
\end{tabular}

The potential influence of CAV technologies on vehicle fuel efficiency is based on a review of numerous studies as discussed in Section 3.1.2. The identified CAV technology influences include: 
- Drive profile and traffic flow smoothing

- Faster travel

- Intersection vehicle-to-infrastructure (V2I)/infrastructure-to-vehicle (I2V) communication

- Collision avoidance

- Platooning

- Vehicle/powertrain resizing.

Faster travel in CAVs may lead to an increase in fuel consumption, while the other factors studied lower fuel consumption. To account for the fact that the efficiency effects of many of these features depend on the driving conditions, the study's estimated fuel consumption rate impacts vary by road type (city vs. highway) and travel time (peak vs. off-peak times) (see Sections 3.1.2 and 3.1.3 for details). This analysis focuses on CAV technology impacts in conventional ICE powertrain vehicles, and does not consider the combined influences of electrification, alternative fuels and CAVs technologies on vehicle petroleum consumption. The influence of CAV technologies on vehicle energy consumption is expected to differ by powertrain (Michel et al. 2016), but few studies were found quantifying this dependence over the range of potential efficiency-influencing CAV features.

Figure 4 shows the estimated upper bound (UB) and lower bound (LB) impacts on the average vehicle fuel consumption rate in each scenario. The plot includes "negative fuel consumption" bars to illustrate the magnitude of different CAV features' reduction of the baseline fuel consumption rate from the Conventional scenario. These were combined with the fuel consumption increase due to faster travel to give the net consumption rate. The black line at the end of each bar in the figure indicates this net rate in units of gasoline consumed per 100 miles traveled. Note that vehicle/powertrain resizing offers large potential reductions, but that the bounds are wide, indicating large uncertainty in this factor. Similarly, potential reductions due to drive profile and traffic flow smoothing are large but also uncertain.

Summing these impacts over the total U.S. LDV stock, accounting for the bounds on VMT described above, and the dependence of fuel consumption rate impacts on road type and peak vs. non-peak travel, yield bounds on total national LDV fuel use. Combining the largest VMT increases with the smallest efficiency improvements gives the upper bound, and combining the smallest demand increases with the largest efficiency gains yields the lower bound for total LDV fuel use. Figure 5 shows these upper and lower bounds for the CAV scenarios relative to the base Conventional scenario. 


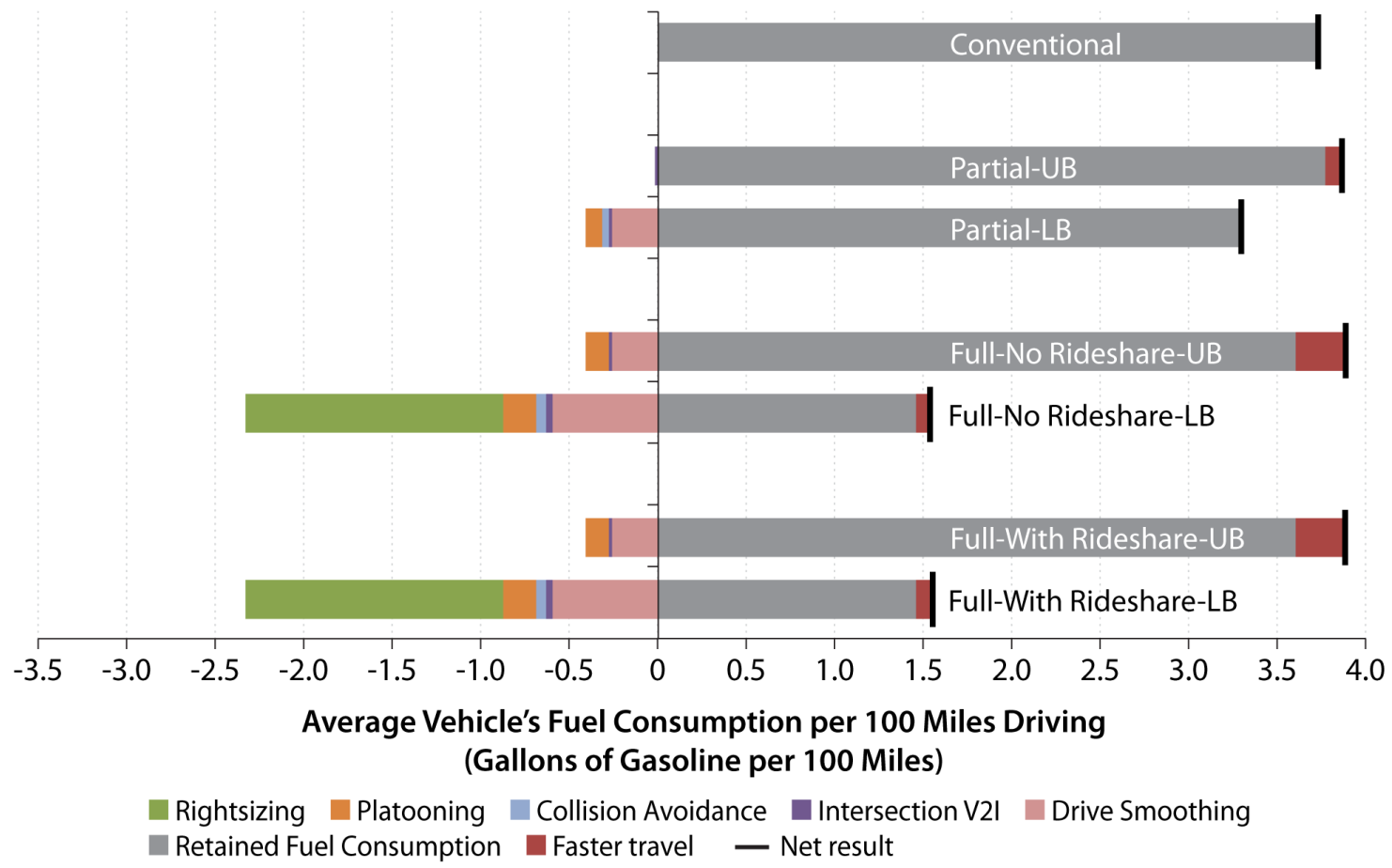

Figure 4. Estimated bounds on vehicle fuel consumption rate (gallons of gasoline per 100 miles of driving) for each of the scenarios

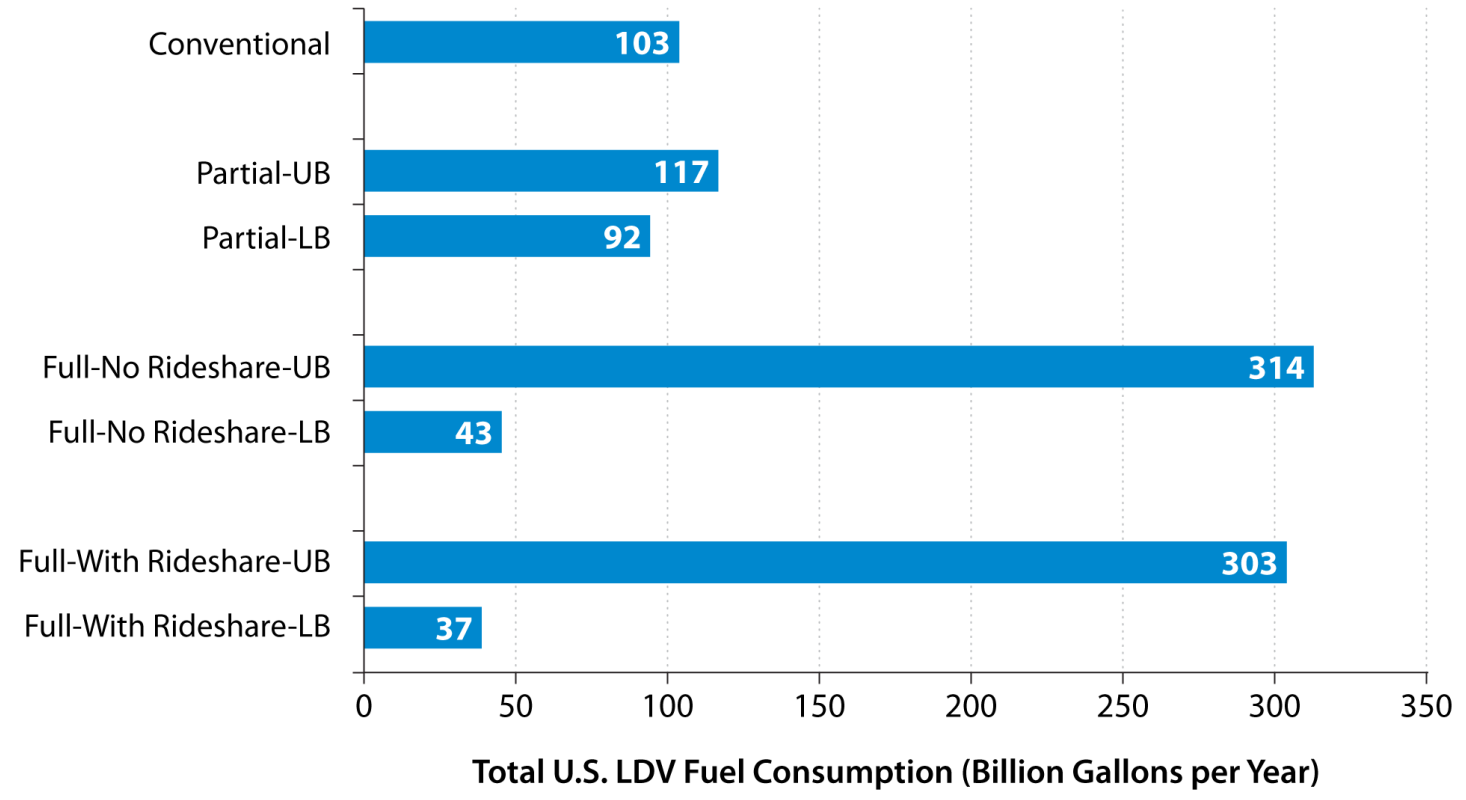

Figure 5. Upper bound (UB) and lower bound (LB) estimates on total U.S. LDV fuel use per year under each CAV scenario compared with the Conventional base scenario 
In this analysis, the partial automation scenario shows a relatively modest range of impacts, on the order of $\pm 10 \%$ for the upper and lower bounds relative to the base scenario. However, the full-automation scenarios show wide separation between the bounds on U.S. LDV fuel use, reflecting the large uncertainties in fully automated CAV influences on both VMT and vehicle fuel efficiency. The upper bound for the Full-No Rideshare scenario represents the highest increasing fuel use case with triple the annual fuel use of the base scenario. The lower bound of the Full-With Rideshare scenario represents the lowest decreasing fuel use case with less than $40 \%$ of the base scenario's fuel use.

It would be possible to reduce the lower bound fuel use even further by combining efficiencyimproving CAV features with advanced powertrain technologies such as hybrid electric and/or plug-in electric vehicles. Insufficient analyses to date on the combined effects of CAV technologies with advanced powertrains prevented an explicit estimation as part of this study, though some early studies have suggested that the combination of CAVs with vehicle electrification could achieve lower bound fuel savings in excess of 90\% (Brown et al. 2014, Greenblatt and Saxena 2015).

\subsection{Estimated Bounds on CAVs' Costs to Consumers}

This subsection summarizes the report's analysis of potential CAV technology impacts on costs to consumers. Figure 6 illustrates the structure of this analysis, which builds upon the estimated ranges of CAV impacts on travel demand and efficiency within each of the established scenarios.

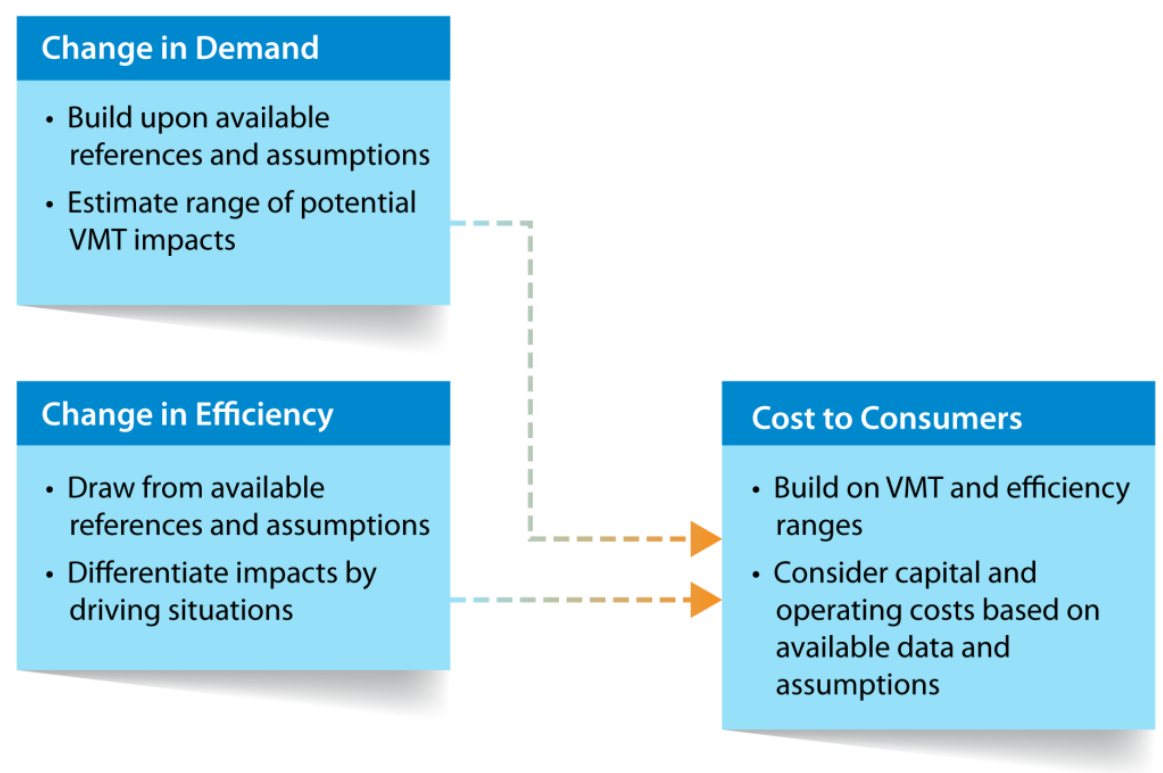

Figure 6. Visualization of the analysis process to estimate bounds on costs to consumers for each of the CAV scenarios 
As with the energy impact analysis, the evaluation of potential CAV technology impacts on costs to consumers builds upon relevant information extracted from literature for separate cost categories. Section 3.2 provides a detailed description of the available data and assumptions supporting the analysis. Costs in the following categories, spanning vehicle purchase and operation, are considered:

- CAV technology cost increment to vehicle purchase price

- Maintenance and repair costs

- Connectivity service fee

- Insurance premiums

- Costs of crashes not covered by insurance

- Fuel cost

- Cost of travel time.

While estimated cost impacts are highly uncertain, to calculate the range of potential CAVs' impacts on consumer costs the lower and upper range estimates for each cost component are combined with the fuel consumption rate and vehicle occupancy assumptions associated with the respective LB and UB cases for each of the considered CAVs scenarios. As mentioned previously, no distinction is made between privately owned and shared CAVs. Even though shared vehicles would be expected to have much higher annual mileage than private vehicles, they are assumed here to achieve comparable lifetime mileage as privately-owned vehicles (and simply be replaced more frequently).

Figure 7 illustrates the resulting upper and lower bounds on total costs per passenger mile for each CAVs scenario relative to the Conventional scenario. Under this comparison most of the CAVs cases show substantial decreases in costs to consumers - for the lower end assumptions in the Full-With Rideshare scenario the net cost reduction relative to the baseline is roughly $60 \%$. Note that the significant reductions in estimated consumer costs are driven largely by reductions in travelers' perceived travel time costs, which in addition to being highly influential is a highly uncertain factor. The only cost-increasing case relative to the baseline is produced by the upper end assumptions for the Partial automation scenario. For this case assumptions of higher vehicle purchase, repair and connectivity service costs together with little or no benefits with respect to insurance and travel time costs result in a net 3\%-4\% cost increase relative to the baseline. 


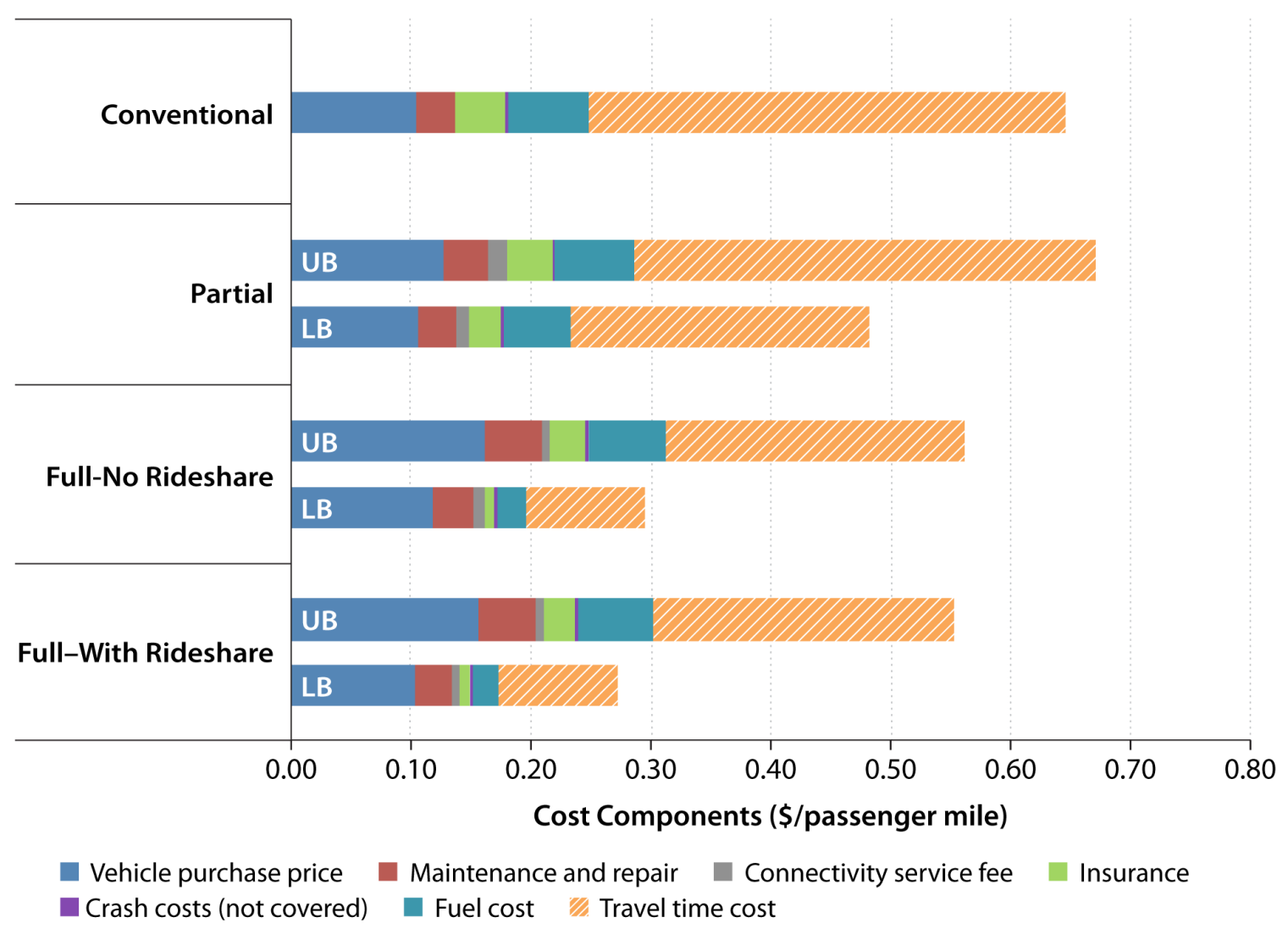

Figure 7. Estimated bounds on consumer cost components under the Conventional and selected CAV scenarios

It should be noted that the approach taken here provides useful bounds on the potential range of cost impacts, but that in reality the lowest cost per passenger mile cases are likely to be associated with the highest increases in travel (and conversely the highest cost cases are likely to be associated with the lowest travel increases), because lower travel costs induce travel demand. For simplicity and to avoid confusion, the potential ranges of fuel and cost effects are calculated separately in this report, and the LB vs. UB designations are used to describe the lower vs. upper ranges for both fuel use and cost. Specifically, the LB cost cases combine the lowest cost VMT and fuel consumption cases, and the UB cost cases combine the highest VMT and fuel consumption cases. 


\section{Details on Methodology and on Input Assumptions Extracted from Literature}

This section provides extensive details on the calculation methodology and input assumptions developed for the ranges of impact estimates established in Section 2. Similar to the organization of Section 2, Section 3.1 focuses on these supporting details for the fuel use estimation and Section 3.2 provides the details for the consumer costs estimation.

\subsection{Literature and Methodology Discussion for Potential CAV Impacts on Fuel Use}

The detailed discussion in this subsection corresponds to the results summarized in Section 2.1 and the fuel use estimation process illustrated in Figure 2. The discussion is further divided into three parts: review of the literature and estimates adopted for the range of possible travel demand impacts from CAV technologies (Section 3.1.1), review of the literature and estimates adopted for the range of energy efficiency impacts from CAV technologies in different driving conditions (Section 3.1.2), and a detailed discussion of the methodology used to aggregate CAV VMT and efficiency impacts in different driving conditions into overall national-level impact estimates (Section 3.1.3).

\subsubsection{Literature on Travel Demand Impact of CAV Technologies}

Possible changes in travel demand due to connectivity and increased automation are uncertain, and estimates from the few studies of travel demand impact vary widely, especially for high levels of automation. Brown et al. (2014), MacKenzie et al. (2014), Fagnant and Kockelman (2015a), and Wadud et al. (2016) reviewed several such sources, and list possible ways that vehicle automation may impact travel behavior, including increased travel induced by a decrease in generalized travel costs, a lower perceived cost of travel time, increased travel by underserved population segments (e.g., young children, elderly and/or disabled individuals), mode shift, ridesharing, and changes in parking patterns due to self-parking cars or empty travel by driverless cars.

Correspondingly, the potential effects of CAVs on travel demand are discretized into the following categories for this analysis:

- Less hunting for parking

- More travel due to it becoming easier (from faster travel and decreased cost of travel)

- Increased travel by populations whose transportation needs are currently underserved

- Mode shift from walking, transit and regional air

- Increase in ridesharing

- Increased empty miles traveled by automated vehicles.

For each of these categories, the analysis draws from previous studies' estimated magnitudes of potential CAV technology influences. Effects in some categories are assumed to influence only city driving, and some estimates are adjusted to approximately account for interaction among effects and to harmonize the estimated influence with the assumptions made for each scenario, as 
discussed below. As CAVs technologies are adopted, they may simultaneously influence VMT through each of the above categories. Here, for simplicity, the influence of each effect is calculated in the order listed above, with assumptions about the interactions with previously considered effects. The analysis assumes that the influence of some factors is additive (an increment of the baseline VMT), and that some are multiplicative (an increase by a given factor applied to the VMT estimated from considering the earlier effects). In each case, the maximum and minimum estimates are taken as the upper and lower bounds, respectively.

Partial automation, including driver assistance capabilities, is considered separately from full automation, which would allow vehicles to travel without the driver paying attention, or even without a driver present. Full automation is assumed to have a much larger potential influence on travel behavior than partial automation, consistent with assumptions in the literature reviewed.

\section{Less Hunting for Parking}

\section{Assumptions:}

- Partial automation: 2\%-5\% VMT reduction during city driving

- Full automation: 5\%-11\% VMT reduction during city driving

Shoup (2006) estimated that $2 \%-11 \%$ of VMT in a central urban area are spent hunting for parking. Connectivity technologies can enable information sharing between vehicles and infrastructure, providing accurate parking information and thus reducing VMT driven while hunting for parking. Shared fully automated vehicles may have less need for parking at all (though this would be traded off against increased empty VMT). Brown et al. (2014) estimated up to $5 \%$ of fuel in an average passenger car may be consumed searching for parking. Based on the literature, a simplifying assumption is adopted that fully automated vehicles can achieve 5\%$11 \%$ VMT reduction in city driving from reduced circulation for parking. It is assumed that the same reduction could occur during peak traffic periods when congestion is high and off-peak travel periods when most parking spaces may be full. Partially automated vehicles would similarly realize some level of fuel savings due to the improved ability to accurately locate available parking spaces, but by lacking automatic implementation the range of expected savings would be somewhat less. In the absence of differentiation from literature between partial vs. full automation's ability to reduce VMT from hunting for parking, this report simply adopts 5\% (the lower bound assumption from full automation) as the upper bound assumption for partial automation, and 2\% (the lower end of Shoup's estimate for parking-related VMT) as the lower bound assumption for partial automation (each percentage again relative to total city driving). These assumptions could certainly be refined as further studies explore this topic.

\section{Easier Travel}

\section{Assumptions:}

- Partial automation: $4 \%-13 \%$ increase in VMT

- Full automation: 20\%-160\% increase in VMT

Easier travel includes the influence of being able to more quickly reach destinations (due to capacity increases and fewer crashes) and decreased perceived cost of travel (such as from different valuation of travel time in automated versus manually driven vehicles). If crashes and congestion are reduced, travel may be quicker and more reliable, and travel demand may 
increase. Less congestion and fewer crash delays would effectively increase capacity, which could also induce increased travel. Travel demand induced by increased capacity was reviewed by Cervero (2001), who reported a range of long-run elasticities of urban VMT with respect to lane-miles of 0.46 to 0.94 . This elasticity is an indicator of the sensitivity of VMT to a change in lane-miles, defined as:

$$
\frac{V M T}{V M T_{0}}=\left(\frac{x}{x_{0}}\right)^{\varepsilon}
$$

where:

$$
\begin{aligned}
& \varepsilon: \text { elasticity } \\
& V M T: \text { VMT with change in lane miles } \\
& V M T_{0} \text { : original VMT } \\
& x: \text { lane-miles } \\
& x_{0}: \text { original lane-miles }
\end{aligned}
$$

However, capacity increases from vehicle connectivity and automation differ from an increase in lane-miles; they may increase throughput on existing lanes, but do not increase network connectivity or accessibility to more destinations. Hymel et al. (2010) estimated elasticities of VMT with respect to lane-miles, disaggregating the VMT change due to a change in road-miles from that due to a change in lane-miles (at constant road-miles), and reported much lower values for the elasticity with response to road-miles: 0.037 short-run, 0.186 long-run, and attributed only $40 \%$ of this to increase in lane-miles. This indicates that increasing capacity by vehicle connectivity and automation without increasing network connectivity with new roads would induce less VMT increase than the elasticities reported by Cervero would imply; however, the influence of CAVs on future VMT is highly uncertain, dependent on how CAVs will be adopted and used.

Childress et al. (2015) assessed potential changes in travel patterns in the Puget Sound region in scenarios modeled using an activity-based travel model. Scenarios analyzed included a 30\% increase in roadway capacity, which resulted in a 3.6\% increase in VMT, a decrease in perceived value of travel time cost of $35 \%$ for the highest-income households in addition to the $30 \%$ increase in capacity, which gave a VMT increase of 5.0\%. In a third scenario, which assumed that everyone owned an automated vehicle (none of which was shared), a $30 \%$ increase in roadway capacity, and a 50\% reduction in parking costs, VMT increased $19.6 \%$, with an increase in average commuting distance of $60 \%$. Notably, in the third scenario Childress et al. found increased delays (a $17.3 \%$ increase in vehicle hours traveled). They remarked that people may be more willing to travel under congested conditions in automated vehicles.

Gucwa (2014) used a different activity-based model to simulate travel in the San Francisco Bay area under different assumptions about the resulting capacity increases from automation (none, 
$10 \%$, and doubling) and travel time costs ranging as low as $50 \%$ of the cost of travel time in a current car. He estimated a 4\%-8\% increase in VMT in these scenarios. In an additional scenario, he estimated a $14.5 \%$ increase if a zero cost of travel time was assumed for traveling in an automated vehicle. Neither Gucwa nor Childress et al. modeled changes in land use, e.g., changes in spatial distributions of residences or job locations. With such changes included, VMT increases could be significantly higher.

In a recent report, KPMG projected personal travel in the U.S. to increase by approximately 500 billion PMT by 2050 due mostly to population growth, but PMT could increase by twice this amount due to increased use of mobility as a service enabled by connectivity and automation, especially by persons 16-24 years old and 65-84 years old (KPMG 2015a). Corresponding increases in VMT are highly uncertain due to the uncertainty in average vehicle occupancy, depending on the adoption of ridesharing and automated vehicles that may travel unoccupied part of the time.

Brown et al. (2014) considered travelers' time budget, based on the observation of Schafer et al. (2009) that the time that people are willing to spend traveling is consistent even across different societies. They conjectured that if people could travel faster, they might choose to live farther from their routine destinations or travel more. They estimated that VMT could increase by approximately $50 \%$. They noted that this did not include the potential increase in time spent traveling that might result from automation.

A wide range of potential VMT impacts was estimated by MacKenzie et al. (2014): a VMT increase of 4\%-13\% with partial vehicle automation (e.g., driver assistance), and 30\%-160\% for full automation. A large component of the VMT impact from full automation was due to the change in the value of travel time (or perceived cost of travel time). They assumed a range of travel time cost in fully automated vehicles from $20 \%-50 \%$ of the value of time spent driving a conventional vehicle. They also noted that reduced insurance costs, resulting from reductions in on-road accidents, and perhaps a lower energy cost per mile could contribute to increased VMT. They assumed an elasticity relationship between VMT and generalized cost to estimate the potential increase in VMT resulting from possible changes in perceived costs. Their estimated VMT increase ranged as high as $156 \%$ for full automation with an elasticity as extreme as -2.0 . They stressed the uncertainty in this estimate and noted their assumption that automation did not increase vehicle purchase costs. They analyzed other possible outcomes with intermediate VMT and energy impacts. In a more recent version of this paper these same authors estimated the upper bound on VMT with full automation to be a $60 \%$ increase, based on an elasticity of VMT with respect to cost of -1.0 (Wadud et al., 2016).

For this analysis the bounds given by MacKenzie et al. (2014) are used for partial automation, recognizing the large uncertainty in the elasticity of VMT with respect to cost. For full automation, the lower bound (15\% increase) is taken from Gucwa (2014), and the upper bound (160\% increase, rounded up from 156\%) is taken from MacKenzie et al. (2014). These are applied as a multiplicative factor to the VMT bounds following consideration of less hunting for parking to avoid double counting. These factors are applied to VMT in city and highway and in peak and off-peak conditions. 
Increased Travel by Underserved Populations

Assumptions:

- Partial automation: no change in VMT

- Full automation: $2 \%-40 \%$ increase in VMT

Possible changes in travel by persons whose transportation needs are currently not well met is difficult to estimate due to lack of sufficient data on why certain population segments travel less than others. MacKenzie et al. (2014) examined data from the 2014 National Household Travel Survey (NHTS) (Federal Highway Administration [FHWA]) and observed that VMT per driver peaks at age 44, then declines steadily through age 62 and more steeply after that. They assumed as an upper bound that the accelerated decline at ages above 62 represented travel that is foregone due to impaired driving abilities. This travel demand could be met by fully automated vehicles. By extrapolating the 44- to 62-year-old VMT trend (which they took to represent the natural rate of decline of travel needs) and subtracting this from the VMT per driver at age 62 (which they took to be an upper bound of the desired travel demand for older drivers), they estimated increased travel of $2 \%-10 \%$.

In a slightly different analysis of the 2009 NHTS, Harper et al. (2015) assumed non-drivers would travel as much as the drivers within each age group, that the elderly would travel as much as drivers without medical conditions aged 19-64, and that drivers with medical conditions would travel as much as drivers without medical conditions within each age group. By analyzing three groups of non-drivers - 19 and older, elderly drivers without a medical condition, and drivers 19 and older with a medical condition - they estimated that the underserved could increase VMT by as much as $12 \%$ by using fully automated vehicles.

Brown et al. (2014) also examined data from the 2009 NHTS and from the 2003 Bureau of Transportation Statistics publication "Freedom to Travel." They estimated that if all age segments traveled as much as the top decile within each segment, this would result in as much as a $40 \%$ increase in travel.

These increases are applied to the baseline VMT (after consideration of less hunting for parking). Because the estimate is based on the size of the underserved population, the upper bound travel increase from currently underserved individuals would not change due to overall easier travel for the wider population.

\section{Mode Shift from Walking, Transit and Regional Air}

\section{Assumptions:}

- Partial automation: no change in VMT

- Full automation: 0-16.4 billion mile increase in city VMT (from walking), 0-56.5 billion mile increase in city VMT (from transit), and 0-79.8 billion mile increase in highway VMT (from regional air)

Little work has been reviewed that gives estimated shifts in mode choice by travelers from walking, transit or regional air to CAVs. Upper bounds are estimated by considering the potential effects of $100 \%$ shift from these modes to single-occupancy CAVs. No mode shift, with no resulting change in VMT, is taken to be a lower bound for full automation (as well as the mode 
shift impact from partial automation), although it may be possible for CAVs to help some travelers access public transit and increase transit ridership. For reference, the U.S. Energy Information Administration 2014 Annual Energy Outlook Reference case gave total LDV VMT as 2.785 trillion vehicle-miles (U.S. Energy Information Administration 2014).

For estimating the upper bound on a shift from walking to CAVs, the 2009 NHTS (FHWA) reports for walking 27.943 billion person-miles per year. Of this, 16.4 billion person-miles were on trips greater than 1 mile, or $0.59 \%$ of LDV VMT per year. Many trips of less than 1 mile may not feasible in motorized vehicles, so for the purposes of the bounding exercise, miles walked on trips of 1 mile or more are included in the upper bound for increased city VMT.

According to the National Transit Database for 2013, transit passenger-miles totaled 56.5 billion miles (FTA n.d.). Shifting all passenger-miles to vehicle-miles represents an increase of $2.0 \%$ in VMT. This increase is assumed to be in city travel only. It therefore represents an increase of $3.7 \%$ in city VMT.

Considering a shift from air travel, an estimate of 79.8 billion passenger miles traveled via domestic flights shorter than 500 miles was obtained from the Bureau of Transportation Statistics TranStats Data Library, in the database "Air Carrier Statistics (Form 41 Traffic) - All Carriers," "Table T-100, Domestic Segments (All Carriers)" for 2014 (Bureau of Transportation Statistics). Shifting all of these passenger-miles to unshared vehicle-miles represents an increase of $2.9 \%$ in VMT. This is assumed to increase VMT only on highways.

\section{Increase in Ridesharing}

\section{Assumptions:}

- Partial automation: no change in VMT

- Full automation: $0 \%-12 \%$ reduction in total VMT, applied to city driving

Ridesharing can provide more mobility at reduced VMT. For example, Santi et al. (2014) analyzed trips by taxis in New York City in 2011 and found that many of the trips (origindestination pairs) could be served with $40 \%$ fewer taxi-miles if rides were shared. Side cases were examined to simulate lower spatial densities, which suggested that the ridesharing would also be effective in areas with lower densities than New York City. How this could be implemented and how many users would be willing to share rides are very uncertain. Brown et al. (2014) cited a review of ridesharing programs (Porter et al. 2013) and estimated that ridesharing could reduce total VMT by as much as $12 \%$. Porter et al. noted that historically, ridesharing programs have had little impact on VMT. However, they further observed that according to the FHWA, average vehicle occupancy was about 1.6-1.7 persons and less than 1.1 persons for work trips, and concluded that ridesharing could potentially reduce VMT by a large amount (FHWA 2011, Porter et al. 2013).

No ridesharing is assumed for partial automation. For the Full-With Rideshare scenario, ridesharing is assumed to take place only in city driving, after estimating changes in city VMT due to faster travel, decreased cost of travel, increased travel by underserved, and mode shifting. A $12 \%$ reduction in total VMT is taken as a lower bound, and zero ridesharing is taken to represent the upper bound. The $12 \%$ reduction, applied to the VMT resulting from the other factors (easier travel, underserved, and mode shift), represents a reduction of 367 billion miles in 
the lower bound case, equivalent to $13.2 \%$ of total VMT in the baseline Conventional case. Applying a reduction to the upper bound of VMT would have been reasonable, but would probably confound various influencing factors, resulting in double counting.

\section{Increased Empty Miles Traveled by Automated Vehicles}

\section{Assumptions:}

- Partial automation: no change in VMT

- Full automation: no ridesharing: $0 \%-11 \%$ increase in city VMT; with ridesharing: $0 \%-$ $5 \%$ increase in city VMT

The possible change in vehicle travel by empty, driverless vehicles has not been thoroughly studied. A driverless vehicle owned by a household could be sent without a driver to pick up family members, to run errands, or to be in a position to be available where needed next to minimize wait time. No quantitative analysis of such use of privately owned CAVs was reviewed. Several studies of shared, self-driving vehicles have analyzed a number of scenarios at the city level and estimated the number of shared vehicles that could replace privately owned vehicles while serving the same transportation needs. These studies also examined the tradeoff between fleet size and waiting times, and some estimated VMT for repositioning of empty, shared CAVs.

Fagnant and Kockelman (2014) used an agent-based model of self-driving vehicles traveling in a square grid representing a notional city to analyze potential travel patterns by users of a fleet of shared self-driving vehicles. Taking trips as given, with a generation rate based on the temporal distribution of the trip start rates in the 2009 NHTS and a trip distance distribution based on the distribution of trips less than 15 miles in the 2009 NHTS, they analyzed scenarios with different trip generation rates, vehicle relocation strategies, network congestion levels, and service area sizes. They concluded that each shared self-driving vehicle could replace about 11 conventional vehicles, with an increase of 5\% to $11 \%$ in VMT for vehicle repositioning. In another study, Fagnant and Kockelman (2015b) considered shared self-driving vehicles with ridesharing. They simulated vehicles operating in the Austin, Texas, area. In several scenarios, repositioning of CAVs led to up to $8.7 \%$ of their VMT empty; while with ridesharing $4.5 \%$ of VMT by CAVs was empty.

The analysis for this report assumes zero empty miles traveled for partial automation. With full automation, car sharing and empty CAV repositioning are assumed to only take place in city driving. As indicated previously, no distinction is made between privately owned and shared CAVs. The upper and lower VMT increases assumed for CAVs without ridesharing is $0 \%-11 \%$ of city VMT, based on Fagnant and Kockelman (2014). More modest increases in city VMT of $0 \%-5 \%$ are assumed for CAVs with ridesharing based on Fagnant and Kockelman (2015b). A lower bound of zero VMT increase is assumed recognizing that some empty CAVs would replace conventional cars traveling to drop off or pick up a passenger, in which case the passenger could potentially be served by a driverless vehicle without a change in VMT. These percentages are applied to VMT after including all other CAV-related VMT factors, but not accounting for potential interactions between factors. Applying these percentages to VMT estimates from above results in VMT increases of 0-488 billion vehicle-miles per year with no ridesharing and 0-222 billion vehicle-miles per year with ridesharing. These represent increases 
of $0 \%-18 \%$ and $0 \%-8 \%$, respectively, of the base case VMT of 2.79 trillion vehicle-miles per year.

Empty miles traveled leads to decreases in occupancy. From the average occupancy of 1.67 (FHWA 2011), a 5\% increase in city VMT is calculated to decrease average occupancy to 1.63, and an $11 \%$ increase gives an average occupancy of 1.58 , with all the above effects taken into account.

\subsubsection{Literature on Fuel Efficiency Impact of CAV Technologies}

Connectivity and automation have the potential to impact vehicle design, driving patterns, and hence fuel efficiency. However, the impacts are uncertain and estimates from existing studies show a wide range. The categories of potential energy impact reported in existing literature include:

- Drive profile and traffic flow smoothing

- Faster travel

- Intersection vehicle-to-infrastructure (V2I)/infrastructure-to-vehicle (I2V) communication

- Collision avoidance

- Platooning

- Vehicle/powertrain resizing.

For each of these categories, the present analysis draws from previous studies to estimate upper and lower bounds of potential CAV technology influences on vehicle fuel efficiency. Due to varying mechanisms by which CAV technologies may provide efficiency benefits, the estimates assume differentiation of the effects between highway vs. city driving and between peak vs. nonpeak travel times. This is because vehicles have different travel patterns (average speed, stop and go, etc.) in highway and city driving, which will influence fuel efficiency. Similarly, traffic patterns vary between peak and non-peak travel times. Heavy traffic typically happens during peak hours, while vehicles generally travel at free flow speed during non-peak hours. The analysis additionally estimates different impacts from partial automation (requiring full-time driver attention and assuming less dramatic changes in vehicle operation) vs. full automation (assuming more dramatic potential changes to vehicle operation, including no need for active human involvement in the driving task). The remainder of this subsection details the adopted assumptions and supporting literature for each of the identified efficiency categories. As further detailed in Section 3.1.3, each efficiency effect is assumed to have a multiplicative impact with all others that apply to a given driving situation, and these effects are applied after first calculating the net VMT impact under each driving situation (per the Section 3.1.1 discussion).

\section{Drive Profile \& Traffic Flow Smoothing}

\section{Assumptions:}

- Partial automation 
○ $0 \%-10 \%$ fuel savings on highway and city driving during peak hours

○ $0 \%-5 \%$ fuel savings on highway and city driving during non-peak hours

- Full automation

○ $10 \%-20 \%$ fuel savings on highway driving during peak hours

- $10 \%-23 \%$ fuel savings on city driving during peak hours

○ $5 \%-10 \%$ fuel savings on highway driving during non-peak hours

○ $5 \%-11.5 \%$ fuel savings on city driving during non-peak hours

The potential for eco-driving (i.e., driving with efficiency-maximizing speed and acceleration operating profiles) to save fuel is well understood by the transportation research community. CAV technologies have the potential to harness and expand upon such efficient driving benefits by having vehicles automatically implement efficiency maximizing driving profiles and by coordinating with other vehicles on the road to make optimized driving decisions that smooth overall traffic flow and benefit the entire driving fleet.

Barth and Boriboonsomsin (2009) utilized traffic simulation models to investigate fuel consumption impacts of coordinated eco-driving. The coordinated eco-driving system uses a virtual traffic management center to control vehicles' speed and acceleration behavior. Barth and Boriboonsomsin simulated a mixed fleet of vehicles on southern California highways and reported that 10\%-20\% fuel and carbon dioxide emissions reduction could be achieved in congested highway traffic. However, they also found that as the traffic reaches free flow, the fuel benefits become diminished. In a similar study for city driving, Barth (2013) found that such a coordinated eco-driving system could achieve $5 \%-10 \%$ fuel savings under congested city traffic conditions.

Li and Gao (2013) explored impacts of speed synchronization through connectivity in a series of micro-simulation modeling studies. Their main purpose was to find the optimal control strategy for maximizing fleet-level average fuel economy in a vehicle connectivity environment. Their results indicated that gasoline vehicles could achieve 10\% fuel savings (and that hybrid electric vehicles could achieve $33 \%$ savings).

Two research projects conducted at the Virginia Tech Transportation Institute (Rakha, Ahn, and Park 2012; Rakha, Kamalanathsharma, and Ahn 2012) also tried to estimate potential fuel impacts of vehicle-to-vehicle communication and coordination. The system proposed involved complex optimization logic incorporating roadway characteristics, lead vehicle information, vehicle acceleration capabilities, and microscopic fuel consumption models to generate a fueloptimal speed profile for each individual vehicle in the fleet. Through simulation they demonstrated that $8 \%-23 \%$ fuel savings could be achieved depending on the vehicles' travelling speed, congestion level and design characteristics.

Synthesis of the reviewed literature results, taking into consideration the conditions under which each set of experiments was performed, led to selection of the efficiency improving assumptions from drive profile and traffic flow smoothing summarized in the above bullet list. 


\section{Faster Travel}

\section{Assumptions:}

- Partial automation: 0\%-10\% fuel increase for highway driving during non-peak hours

- Full automation: 10\%-40\% fuel increase for highway driving during non-peak hours

Automation can help maintain safety during high speed driving. Given that travelers will typically select faster travel options when given the choice, automation may therefore lead to higher highway driving speeds than currently occur with manual driving. It is well understood that as driving speeds increase above 50 or $60 \mathrm{mph}$, aerodynamic drag comes to dominate vehicle power demands and this drag force grows exponentially at higher and higher speeds. Wadud et al. (2016) studied the potential impacts of increased highway travel speeds due to automation technologies through a driver's value of time analysis. They assumed that, under vehicle automation, drivers will increase their speed until the marginal value of time saved just matches the marginal cost of increased fuel consumption. They suggested that drivers will increase their speed to about $80 \mathrm{mph}$ in the absence of a speed limit, and noted that this compared reasonably well with the average travel speed of $88 \mathrm{mph}$ observed on sections of the German Autobahn where there is no speed limit today (Scholz et al. 2007). They adopted the speed-fuel consumption relationship of a typical car (Berry 2010) and concluded that fuel consumption on the highway could increase by $20 \%-40 \%$.

Brown et al. (2014) similarly examined potential increases in highway travel speeds, and estimated that speeds could increase to $100 \mathrm{mph}$ (somewhat higher than the current average manually driven speeds on sections of the Autobahn). Referencing analysis by Hwang et al. (2013), which demonstrated a roughly 14\% decrease in fuel economy for every $10 \mathrm{mph}$ increase in highway speed, Brown et al. estimated that the increase in highway fuel use from faster travel could even exceed 40\%. However, as also acknowledged by Brown et al., such large speed increases would very likely be accompanied by vehicle aerodynamic and/or powertrain changes that could moderate the fuel use impact. This report therefore selects $40 \%$ as the upper bound fuel increase due to faster travel, and applies this figure only to non-peak hour highway travel.

Under partial automation, drivers may not even increase their speed by $10 \mathrm{mph}$ because they still share a major part of control responsibility. Therefore, $10 \%$ is selected as the upper bound fuel increase due to faster travel for partial automation (again only during non-peak highway travel), and $0 \%$ is selected as the lower bound. With no clear literature justification for establishing a lower bound on the full automation faster travel fuel impact, the upper bound from partial automation (10\%) is adopted for this lower bound. This maintains a differentiation between the hypothetical partial vs. full automation scenarios, and this fallback assumption approach is similarly applied to other features where the literature review failed to suggest other specific alternatives.

\section{Intersection V2I/I2V Communication}

\section{Assumptions:}

- Partial automation: $1.8 \%-2 \%$ fuel savings for city driving

- Full automation: $2 \%-6 \%$ fuel savings for city driving 
Another advantage of automation is that it enables communication with infrastructure, particularly at intersections with traffic lights. This communication provides information for vehicles to optimize their driving pattern and thus eliminate stopping at an intersection. Fuel consumption of vehicles is very high at low speeds; therefore, communication at intersections has the potential to reduce fuel consumption. In addition, the energy benefits depend on the penetration of automation technologies. In studies conducted by the University of California, Riverside and the University of New South Wales, Australia (Yelchuru et al. 2014, Yelchuru and Waller 2014), the researchers used vehicle micro-simulation models to estimate the potential impact of eco-traffic signal timing on vehicle fuel savings and the associated optimal signal timing strategies. They concluded that when $100 \%$ of vehicles were connected, $2 \%-6 \%$ fuel savings can be achieved on an average vehicle. In a study conducted by the FHWA (Zimmerman et al. 2000), the authors evaluated vehicle travel patterns before and after a user-information notice system was installed at several signalized intersections in the Phoenix metropolitan area. Based on the empirical data, they concluded that delay was reduced $6.2 \%$, resulting in $1.8 \%$ fuel savings based on a relationship between vehicle speed and fuel consumption. Drawing from these results, this report adopts $1.8 \%-2 \%$ as the fuel savings range from $\mathrm{V} 2 \mathrm{I} / \mathrm{I} 2 \mathrm{~V}$ for partial automation in city driving, and $2 \%-6 \%$ as the comparable range for full automation.

\section{Collision Avoidance}

\section{Assumptions:}

- Partial automation: $0 \%-0.95 \%$ fuel savings on any road type and time of day

- Full automation: 0\%-1.9\% fuel savings on any road type and time of day

Collision avoidance systems are designed to prevent vehicles from getting into collisions. The technology relies on vehicle-mounted sensors that monitor the relative position of surrounding vehicles and other obstacles to provide safety benefits to drivers. In addition to the obvious individual benefits of avoided accidents, elimination of the subsequent traffic jams caused by these accidents provides a collective fuel savings benefit. While the fuel savings benefit of collision avoidance systems is not well studied in existing literature, the Mobility Report produced by the Texas A\&M Transportation Institute (TTI) provides some relevant insights. TTI regularly publishes its mobility report to provide a comprehensive analysis of traffic conditions in over 400 urban areas across the United States, and their 2012 report included specific analysis of accident-induced congestion (Schrank et al. 2012). Specifically, TTI used a dataset of traffic speeds from INRIX, a private company that provides travel time information. The dataset gives annual average traffic speed on each section of road for every 15 minutes of each day. TTI incorporated the INRIX speed data with the volume inventory from FHWA's Highway Performance Monitoring System to calculate travel delay statistics on each section of road. According to Schrank et al., 1.9\% of fuel by the LDV fleet was wasted due to accident-created traffic congestion nationwide. The analysis in this report therefore takes $1.9 \%$ as the upper limit of fuel savings by collision avoidance technology for full automation.

Relevant studies for bounding the potential effectiveness of partial automation collision avoidance technologies include an effort by Najm et al. (2006) at the U.S. Department of Transportation's Volpe National Transportation System Center investigating the effectiveness of an Automotive rear-end Collision Avoidance System (ACAS). This ACAS integrates forward collision warning and adaptive cruise control functions for LDV applications. The ACAS 
underwent a field operational test based on a sample of 10 vehicles used by 66 drivers with appropriate gender and age diversity. Their results show that the ACAS system has the potential to prevent about $10 \%$ of all rear-end crashes. For reference, the National Transportation Safety Board reported that there were over 1.7 million rear-end crashes in the U.S. in 2012 (NTSB, 2015).

Moore and Zuby (2013) from the Insurance Institute for Highway Safety obtained similar results using another approach. The objective of the study was to examine how individual collision avoidance features affected losses under a variety of insurance coverages for vehicle damage and injuries. They utilized a regression analysis model to quantify the impact of collision avoidance systems on accident rates, using a comprehensive dataset provided by auto insurance companies. They found that collision avoidance systems can result in a $10 \%-14 \%$ reduction in accident rates, by controlling all other characteristics of drivers and attributes of vehicles.

The range of benefits from collision avoidance systems reported by these studies may be taken as a starting point for the assumed range of accident reduction benefits from future partial automation vehicle systems. Given that accident avoidance effectiveness in future systems could continue to increase, this study assumes as an upper bound that partial automation could reduce $50 \%$ of accidents and thus achieve $0.95 \%$ fuel savings $(50 \%$ of the full $1.9 \%$ estimate for accident-induced congestion). However, given the uncertainties and the relatively small numbers involved, $0 \%$ is retained as the lower bound assumption for potential fuel savings from both partial and full automation collision avoidance systems.

\section{Platooning}

\section{Assumptions:}

- Partial automation: $0 \%-12.5 \%$ fuel savings on highway driving during non-peak hours

- Full automation: $12.5 \%-25 \%$ fuel savings on highway driving during non-peak hours

Automation and connectivity technologies can enable safe and effective implementation of vehicle platooning (the practice of multiple vehicles following one another closely to reduce aerodynamic resistance, and thus fuel consumption). This strategy is attractive given the large portion of fuel demand attributed to overcoming aerodynamic drag during highway driving. Specifically, Kasseris (2006) reported that aerodynamic drag accounts for $50 \%-75 \%$ of tractive energy requirements in highway driving.

Schito and Braghin (2012) conducted a series of experimental and numerical analyses of platooning light-duty vans to understand the impacts on traffic patterns and fuel efficiency. They found that drag forces were reduced by around $45 \%-55 \%$ on each van. Combining this with the assumption that $50 \%$ of tractive energy is used to overcome drag resistance yields a $22.5 \%-$ $27.5 \%$ potential platooning energy savings estimate. Zabat et al. (1995) also evaluated platooning fuel savings through a series of wind tunnel tests and numeric simulations using a passenger van. They found that the average fuel savings per vehicle ranges from $10 \%$ to $30 \%$, with the majority of scenarios between $20 \%-25 \%$, depending on the platooning space, number of vehicles, and other variables. Wadud et al. (2016) estimated the effects of platooning on energy intensity by translating the reduction in aerodynamic drag achieved by platooning to fuel savings. They reported $20 \%-60 \%$ reduction in aerodynamic drag forces from their platooning literature review. Based on the reported contribution of aerodynamic drag to tractive energy 
requirements in highway driving, and FHWA statistics reporting that highway travel comprises $33 \%-55 \%$ of distance traveled (Kasseris 2006), LDV fuel savings could range between $3 \%$ to $25 \%$.

Taking the upper end of these literature review estimates, this study assumes a maximum platooning fuel savings potential of $25 \%$ for fully automated vehicles, though only on non-peak hour highway driving as non-congested, high-speed conditions provide the best platooning conditions. Platooning fuel savings can also be realized in partial automation implementations. However, the need for some level of human interaction will no doubt limit the maximum savings magnitude and/or duration of time the platooning system is engaged. In the absence of any solid reference for differentiating between partial and full automation platooning fuel savings opportunity, this report simply adopts $12.5 \%$ (half of the upper bound savings estimate for full automation) as the upper bound for partial automation and as the lower bound for full automation (again, only during non-peak highway driving for both automation levels). Given that partial automation platooning systems could have challenges obtaining driver acceptance and compliance to achieve broad use, this report sets $0 \%$ as the lower bound on partial automation platooning fuel savings.

\section{Vehicle/Powertrain Resizing}

\section{Assumptions:}

- Partial automation: 0\% fuel savings

- Full automation: 0\%-50\% fuel savings on any road type and time of day.

Automation technologies have the potential to enable downsizing vehicles without sacrificing safety (Wadud et al. 2016). This downsizing could lead to a significant fuel efficiency improvement. MacKenzie et al. (2014) examined multiple conflicting influences on vehicle weight in two categories: technological changes and improvements in functionality. They observed that the progress in fuel efficiency technology has been offset by growth in vehicle size and feature content. Specifically, they found that, in an average new U.S. 2011 model year car, safety-related attributes were responsible for $7.7 \%$ of weight, and removing them could lead to $5.5 \%$ fuel savings.

Another possible benefit of automation technologies is to facilitate matching of vehicle capacity to individual trip requirements. Wadud et al. (2016) identified this as a potential factor to influence vehicle fuel efficiency. They analyzed a scenario where all single-person trips were served by single-occupancy vehicles, all two-occupants trips were served by compact cars, and 3-4 person and 5-7 person trips were served with midsize cars and minivans. Particularly, the single-occupancy vehicle was assumed to achieve double the fuel economy of a compact car, holding the level of technological sophistication constant. The results showed $45 \%$ savings for the distance-weighted fuel consumption of the whole vehicle fleet.

Brown et al. (2014) separately analyzed vehicle downsizing opportunity, and additionally acknowledged the potential for CAVs' smoother driving demands to interact with sizing decisions for the vehicle powertrain. Current vehicle designs typically use engines with power capabilities far in excess of the power needed to meet average driving demands (because sizing is instead driven by customers' desire for fast acceleration performance). CAVs' powertrain sizing could therefore not only be reduced in response to smaller vehicle sizes, but also in 
response to relaxed demands for fast vehicle acceleration capabilities. An engine sized closer to a vehicle's average power requirements would spend more time operating in its region of highest fuel efficiency, thus improving overall vehicle fuel economy. Brown et al. used two different methods to estimate the potential combined effect of safety-enabled lightweighting and smart vehicle/powertrain rightsizing. The first was combining estimates from Burns et al. (2013) of a large potential for fleet lightweighting (up to 75\%) with multiple references suggesting that every $10 \%$ reduction in weight can result in 6\%-8\% efficiency improvement. This resulted in a roughly $50 \%$ efficiency improvement due to the $75 \%$ mass reduction estimate. Brown et al. also observed that the sales-weighted average fuel economy of modern light-duty vehicles is roughly half that of the 47-mpg 1994 Geo Metro, thus obtaining a consistent 50\% improvement estimate through comparison to an actual lightweight and low-power mass market vehicle.

In practice, the various factors influencing vehicle and powertrain resizing will no doubt interact in complex ways, and there will certainly be limits to the total combined magnitude of this effect. Based on the total cumulative impact estimates from the above literature examples, this analysis assumes $50 \%$ as the upper bound fuel savings that could be achieved for fully automated vehicles. Note also that a potential increase in fuel consumption due to larger CAVs is not considered because that was not mentioned in the literature reviewed, but an increase in average vehicle size associated with CAVs could be possible.

\subsubsection{Methodology to Aggregate National Consumption Impacts}

This subsection details the methodology to roll up the above-described travel demand and vehicle-level fuel consumption effect assumptions to national-level fuel use impact estimates. The equations for these calculations use the following notation:

$i$ : Set of road type I, \{highway, city $\}$;

$j$ : Set of time of day $\mathrm{J}$, \{peak hours, non-peak hours \};

t: Set of technologies T, (note the technologies can be realized at partial and full automation);

$r_{t}^{i, j}:$ Fuel impact estimated by partial automation technology $t$, on road type $i$, and time of day $j$;

$q_{t}^{i, j}$ : Fuel impact estimated by full automation technology $t$, on road type $i$, and time of day $j$

$p_{t}^{i, j}$ : VMT impact estimated by partial automation technology $t$, on road type $i$, and time of day $j$;

$s_{t}^{i, j}$ : VMT impact estimated by full automation technology $t$, on road type $i$, and time of day $j$;

$F C_{0}^{i, j}$ : Original fuel consumption rate (gallon per mile), on road type $i$, and time of day $j$; 
$V M T_{0}^{i, j}$ : Original vehicle miles traveled, on road type $i$, and time of day $j$;

where the impacts, $r_{t}^{i, j}, q_{t}^{i, j}$ are the fractional changes in the fuel consumption per mile over and above the fuel consumption per mile including all impacts considered earlier, that is,

$$
r_{t}^{i, j}=\left(\frac{F C_{t}^{i, j}}{F C_{t-1}^{i, j}}\right)-1, q_{t}^{i, j}=\left(\frac{F C_{t}^{i, j}}{F C_{t-1}^{i, j}}\right)-1
$$

and analogously for $p_{t}^{i, j}$ and $s_{t}^{i, j}$ :

$$
p_{t}^{i, j}=\left(\frac{V M T_{t}^{i, j}}{V M T_{t-1}^{i, j}}\right)-1, s_{t}^{i, j}=\left(\frac{V M T_{t}^{i, j}}{V M T_{t-1}^{i, j}}\right)-1
$$

With the notations introduced above, the baseline passenger car fleet fuel use in the U.S. (with no CAVs) is calculated as:

$$
\sum_{i \in I, j \in J} V M T_{0}^{i, j} * F C_{0}^{i, j}
$$

Thus, the total fuel consumptions under partial automation scenarios are calculated below:

$$
\sum_{i \in I, j \in J}\left[V M T_{0}^{i, j} \prod_{t \in T}\left(1+p_{t}^{i, j}\right)\right] *\left[F C_{0}^{i, j} \prod_{t \in T}\left(1+r_{t}^{i, j}\right)\right]
$$

The total fuel consumptions under full automation scenarios are calculated below:

$$
\sum_{i \in I, j \in J}\left[V M T_{0}^{i, j} \prod_{t \in T}\left(1+s_{t}^{i, j}\right)\right] *\left[F C_{0}^{i, j} \prod_{t \in T}\left(1+q_{t}^{i, j}\right)\right]
$$

The fraction of VMT on city and highway roads at peak and non-peak hours is estimated based on the U.S. Environmental Protection Agency's Motor Vehicle Emission Simulator (MOVES) model values for U.S. national averages (U.S. Environmental Protection Agency 2010). The average fuel economy of LDVs is assumed to be 26.9 miles per gallon. This is consistent with the assumption made in the U.S. Department of Energy Vehicle Technologies Office and Fuel Cell Technologies Office's prospective program benefits assessment (Stephens et al. 2016). This average fuel economy assumption is further extrapolated into fuel economy under different road types based on U.S. Environmental Protection Agency-certified fuel economy. Specifically, the analysis uses the relationship between city/highway fuel economy values with the combined fuel economy to calculate average city and highway fuel economy. It is additionally assumed that traffic congestion occurs during peak hours and free flow patterns occur during non-peak hours. Barth and Boriboonsomsin $(2008,2009)$ suggested adjustment factors to calculate differences in fuel consumption (or greenhouse gas emission, which is a direct indicator of fuel consumption) under congestion and free flow driving. This analysis applies those adjustment factors to calculate fuel economy and fuel consumption values during peak and non-peak hours. The assumptions are shown in Table 3. 
Table 3. Percentage of VMT and Fuel Economy Assumed for a Baseline, Conventional Vehicle by Road Type and Time of Day

\begin{tabular}{llll}
\hline Road Type/Time of Day & VMT \% & $\begin{array}{l}\text { Fuel Economy } \\
\text { (miles per gallon) }\end{array}$ & $\begin{array}{l}\text { Fuel Consumption } \\
\text { Rate (gallon per mile) }\end{array}$ \\
\hline Highway, Peak Hours & $18 \%$ & 29.7 & 0.0337 \\
Highway, Non-Peak Hours & $27 \%$ & 35.0 & 0.0286 \\
City, Peak Hours & $22 \%$ & 21.4 & 0.0467 \\
City, Non-Peak Hours & $33 \%$ & 25.2 & 0.0397 \\
\hline
\end{tabular}

The above formulations, taken together with the assumptions from Section 3.1.2, yield the fuel consumption per mile impacts of different automation technologies at a national level (see Figure 8). The effects are differentiated by partial and full automation.

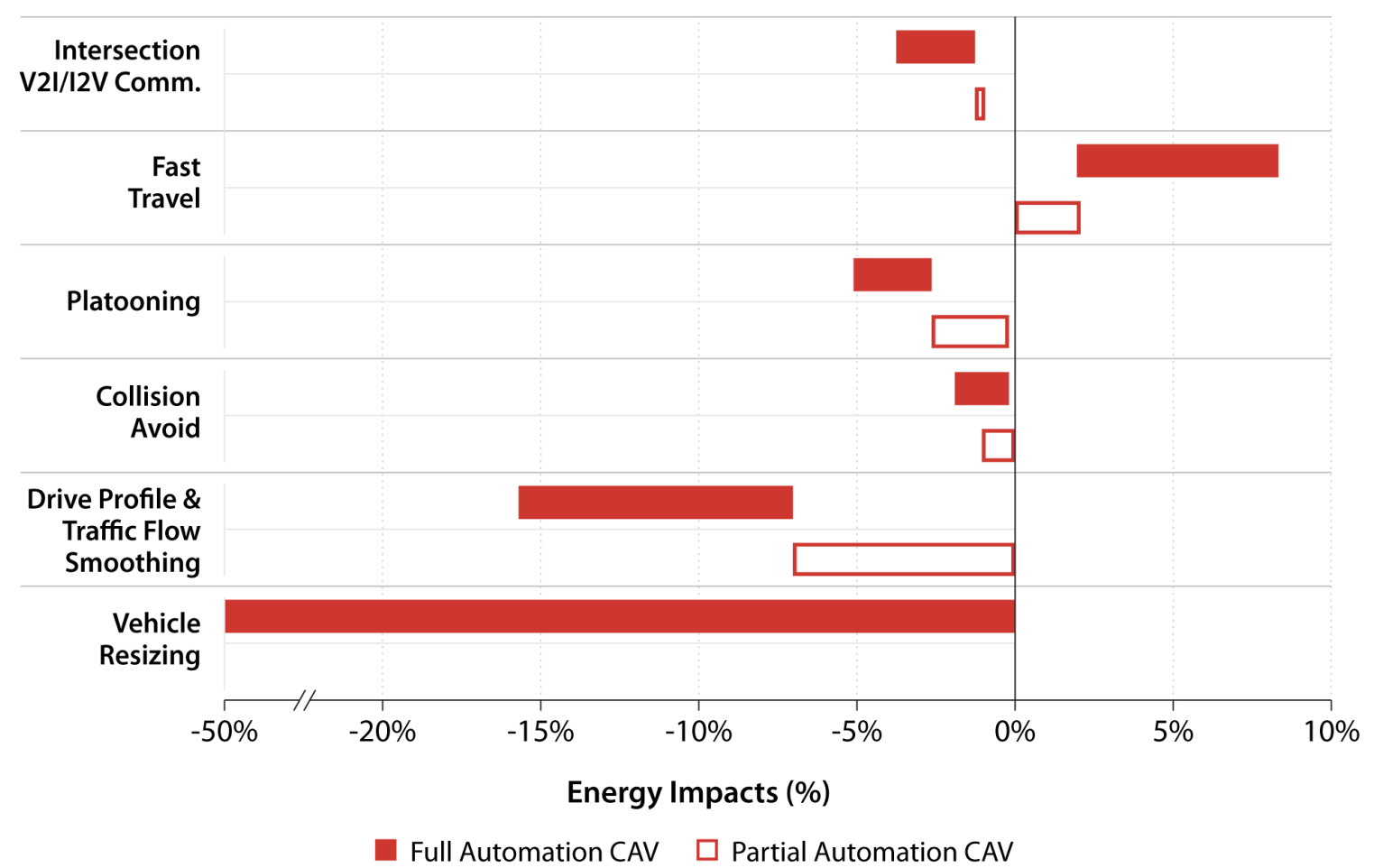

Figure 8. Vehicle-level fuel consumption per mile impact under different automation technologies

\subsection{Literature and Methodology Discussion for Potential CAV Impacts on Consumer Costs}

This subsection returns to the consumer costs analysis (approach visualized in Figure 6), specifically detailing the input assumptions that supported the cost ranges presented in Section 3.2. As indicated in that discussion, the literature review suggested inputs for the following CAV-relevant consumer cost components to consider in the analysis: 
- CAV technology cost increment to vehicle purchase price

- Maintenance and repair costs

- Connectivity service fee

- Insurance premiums

- Costs of crashes not covered by insurance

- Fuel cost

- Cost of travel time.

Estimating the potential range of these major determining factors for CAV costs to consumers will help improve understanding of the actual market potential for CAV technologies. The data sources and estimated ranges of costs for each component are detailed below.

\section{CAV Technology Cost}

\section{Assumptions:}

- The vehicle price increase for the case of partial automation is in the range of $\$ 400$ $\$ 4,500$.

- The vehicle price increase for the case of full automation is in the range of $\$ 2,700$ $\$ 10,000$.

Original equipment manufacturer (OEM) pricing of driver assistance packages is used as a primary data source to infer the technology cost of vehicle automation (Figure 9). These packages include varying technology content, from driver awareness to adaptive cruise control and from lane keeping to Tesla's "Autopilot" system with combined functionality. They are priced in the range of a few hundred dollars to $\$ 4,500$ due to the differences in technology content and OEM pricing strategies.

The estimated technology costs of full automation are primarily based on two recent studies (Boston Consulting Group 2015a, IHS Automotive 2014). The Boston Consulting Group report estimates that the initial pricing of full automation is about $\$ 10,000$, but it declines at an annual rate of $9 \%$ as a result of technology maturation and economies of scale. After ten years of introduction, the price is reduced to $\$ 2,700$. This estimated initial price and decline rate is consistent with estimates from IHS Automotive. 


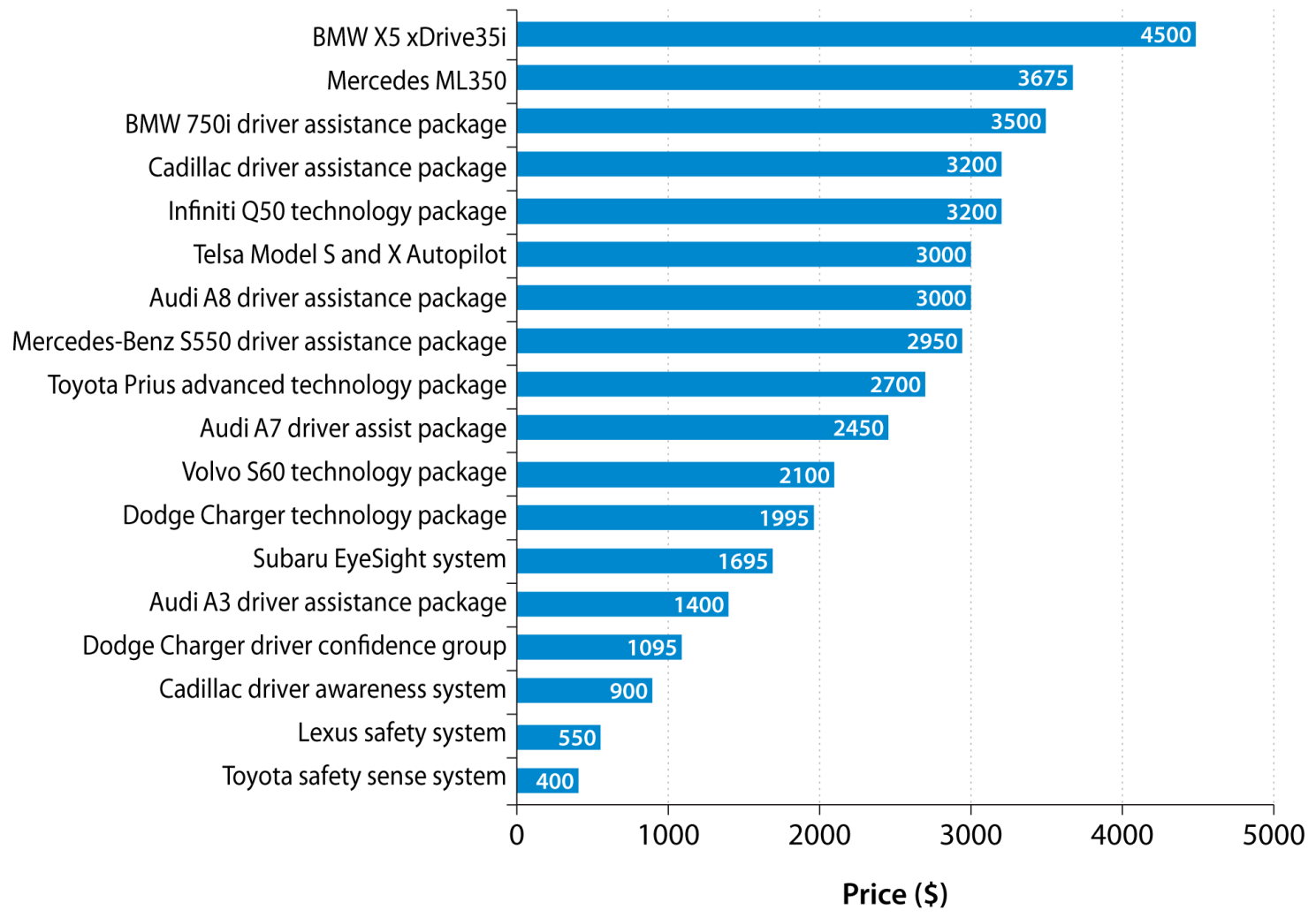

Figure 9. OEM pricing of different driver assistance packages

\section{Maintenance and Repair Cost}

\section{Assumption:}

- Annual maintenance and repair costs for CAVs and conventional vehicles are assumed to be $3 \%$ of total vehicle price.

According to Edmunds.com, maintenance and repair costs are roughly a fixed percentage of the vehicle's purchase price (Edmunds 2016). For example, for a typical family sedan (2015 Honda Accord), Edmunds.com lists the costs of ownership shown in Table 4. The five-year average maintenance and repair cost is $\$ 800$ per year, which amounts to about 3\% of its $\$ 25,000$ purchase price.

Table 4. 2015 Honda Accord Five-Year Ownership Cost

\begin{tabular}{lllllll}
\hline & Year 1 & Year 2 & Year 3 & Year 4 & Year 5 & $\begin{array}{l}\text { 5 Year } \\
\text { Total }\end{array}$ \\
\hline Maintenance & $\$ 287$ & $\$ 500$ & $\$ 278$ & $\$ 869$ & $\$ 1,546$ & $\$ 3,391$ \\
Repairs & $\$ 0$ & $\$ 0$ & $\$ 88$ & $\$ 213$ & $\$ 311$ & $\$ 612$ \\
\hline
\end{tabular}

Source: Edmunds.com 


\section{Connectivity Service Fee}

\section{Assumption:}

- Annual connectivity service fee is assumed to be in the range of $\$ 200-\$ 350$.

The connectivity service fee is assumed to be similar to the subscription fee for navigation and security services (Litman 2015), which is in the range of \$200-\$350. Similarly, the proposed semi-autonomous aftermarket system from Comma.ai will require a subscription fee of \$288/year (Vincent 2016). As the market and technology evolve, we expect to collect more data and further determine the range of the service fee.

\section{Insurance Premiums and Crash Costs Not Covered by Insurance}

\section{Assumptions:}

- Partial automation technologies will reduce insurance premiums by $10 \%-40 \%$

- Full automation technologies will reduce insurance premiums by $40 \%-80 \%$. (The same reductions apply to crash costs not covered by insurance.)

The impacts of CAVs on insurance premiums are highly uncertain over the coming decades. On the one hand, loss per accident may increase due to vehicle price increases and possibly higher travel speeds (Anderson et al. 2016). On the other hand, vehicle automation technologies can potentially reduce accident rates, as acknowledged by some insurance companies. For instance, Allianz offers a $20 \%$ insurance discount for Subaru vehicles that are equipped with the "Eyesight" crash avoidance technology (Boston Consulting Group 2015b).

Based on the statistic that human errors account for $90 \%$ of road accidents and the assertion that full automation can potentially eliminate all human errors, some reports have estimated that insurance premiums can be reduced by as much as 80\%-90\% (McKinsey 2015, Light 2012). Following this reasoning, $80 \%$ is selected as the upper bound insurance premium reduction for this report. Formulating a good lower bound insurance premium reduction estimate is quite challenging given that the impact will be a function of CAVs' safety benefits, market adoption rate, and repair costs. Literature information for all of these considerations is very limited. For the present analysis it is assumed that the lower bound of insurance premium reduction due to full automation is $40 \%$, which is consistent with the estimate by KPMG (2015b). It is further assumed that the range of insurance premium reduction from partial automation is $10 \%-40 \%$.

The insurance premium per year is assumed to be $\$ 928$ for a conventional vehicle, which is the average insurance premium for the United States estimated by the National Association of Insurance Commissioners (2015). A 40\%-80\% reduction in this insurance premium for a fully automated vehicle yields a range of $\$ 186$ to $\$ 557$ per year. Similarly, the annual insurance premium for partially automated vehicles is estimated as $\$ 557$ to $\$ 835$.

This analysis also considers crash costs not covered by insurance, which can include deductibles and other non-insured losses, but at the current stage only insurance deductibles are considered. By car insurance industry estimates (Toups 2011), on average a driver will file a claim for a collision about once every 17.9 years. It was assumed that a driver will carry collision coverage for no more than roughly half of this time, so over the life of a vehicle the driver will have a $50 \%$ chance to pay one deductible. This amounts to a $\$ 250$ additional cost for a conventional vehicles 
assuming a $\$ 500$ deductible. The crash cost not covered by insurance is reduced to $\$ 150-\$ 225$ for partially automated vehicles and $\$ 50-\$ 150$ for fully automated vehicles.

\section{Fuel Cost}

\section{Assumptions:}

- The average fuel cost for conventional gasoline vehicles is $\$ 0.11 / \mathrm{mile}$. Partial automation technologies will reduce fuel cost by $1.7 \%-14.4 \%$, and full automation technologies will reduce the cost by $13.4 \%-76.7 \%$.

The fuel cost (\$/mile) is calculated as the ratio of gasoline price to fuel economy. The gasoline price is assumed to be $\$ 2.93 /$ gallon, and the fuel economy is 26.9 miles per gallon. These numbers are consistent with the U.S. Department of Energy Vehicle Technologies Office and Fuel Cell Technologies Office FY2016 prospective benefits assessment (Stephens et al. 2016).

The percentage of fuel cost reduction from vehicle automation is estimated using the methodology described in Section 3.1.

\section{Cost of Travel Time}

\section{Assumptions:}

- The cost of travel time for the conventional vehicle case is assumed to be $\$ 0.50 / \mathrm{mile}$ for the driver and $\$ 0.25 /$ mile for each passenger.

- Partial automation technologies will reduce the driver's perceived travel time cost by $5 \%-50 \%$ while each passenger's cost remains $\$ 0.25 /$ mile.

- Full automation technologies will reduce the driver's travel time cost by $50 \%-80 \%$, and each passenger's perceived costs are taken as equal to the driver's cost.

How travelers perceive their cost of travel time in an automated driving vehicle is likely one of the most important factors for CAV market adoption. Generally speaking, automated driving frees the human driver from the driving task, and thereby reduces the driver's stress level as well as enabling the driver to do other activities in the car. The degree of stress reduction and productivity enhancement will certainly depend on the driver, the driving situation, and the trip purpose. These issues are being studied, and no estimates are available yet. This analysis adopts the assumption used by Mackenzie et al. (2014) that travel time cost reduction is $5 \%-50 \%$ for the case of partial automation technologies and $50 \%-80 \%$ for the case of full automation technologies. Mackenzie et al. (2014) assumed a value of travel time of $\$ 18$ per hour, which is consistent with a cost of $\$ 0.50$.mile at an average speed of roughly $35 \mathrm{mile} / \mathrm{hr}$.

Presumably, the passenger has no stress of driving and can do some other activities in the car. Thus the travel time cost for the passenger should be less than for an attentive driver. The travel time cost shown in Figure 7 is the overall cost/passenger mile, which is the average cost per person in the car.

\section{Converting to Cost per Mile}

In Figure 7, all cost components are converted to a cost-per-passenger mile basis. The conversion assumes the annual mileage of a conventional vehicle is 12,566 miles (U.S. Energy Information Agency 2014), and the life span of a vehicle is 10 years. Thus, the total lifetime mileage of a 
vehicle is 125,660 miles, which is applied to both conventional and automated vehicles. However, automated vehicles are driven more each year so have a shorter time-based life span. Taking the changes in VMT calculated as described in Section 3.1.1 and assuming the annual distance driven per vehicle changes proportionally, the annual mileage of partially automated vehicles is assumed to range from 12,710 to 14,040 miles, and the annual mileage of fully automated vehicles without ridesharing ranges from 13,810 to 39,550 miles. 


\section{Most Important Factors and Uncertainties for CAVs Impact Estimates}

While modest energy impacts are expected for partial automation and limited connectivity, the potential energy impacts of full automation and widespread connectivity are very large. The bounds estimated here for LDVs range from less than 40 percent to three times the fuel currently used by LDVs in the United States. These wide bounds are the result of uncertainties in several factors that have the potential to greatly influence future energy consumption by CAVs. These factors are discussed in Section 4.1, and the important data gaps that cause large uncertainty in the potential energy impacts are discussed in Section 4.2.

\subsection{Most Important Factors Contributing to Changes in Fuel Use}

Generally, the factors can be grouped into three categories: those that influence (1) vehicle fuel consumption per mile, (2) travel demand or VMT, and (3) CAV adoption. Of the fuel efficiency impacts considered here, vehicle/powertrain resizing offers the largest potential decrease in energy consumption per mile, albeit based on assumptions of radical downsizing. The potential reduction in fuel consumption by changing drive profiles and smoothing traffic flow is also large. Most of the CAV factors considered can potentially decrease fuel consumption per mile with the exception of higher speed travel. Note that an increase in fuel consumption due to larger CAVs was not considered since that was not mentioned in the literature reviewed, but an increase in average vehicle size associated with CAVs could be possible.

The potential influence of CAVs on travel demand is quite large with possible increases due to easier travel being the largest component. Repositioning of empty CAVs could increase VMT, but few estimates of this increase were found in literature, and these estimates were small (a few percent). Increased ridesharing could decrease VMT, but adoption of ridesharing is very uncertain. While current driver assistance technology is being adopted at some level, the future adoption levels of advanced CAV technologies are highly uncertain. Costs for such technologies are currently quite high compared to the cost of a conventional vehicle, but are decreasing rapidly with technology development and are expected to decrease much more if produced at large volumes. However, consumer attitudes and preferences for CAVs are not well understood. The bounds on future energy impacts of fully automated CAVs were estimated here assuming essentially $100 \%$ adoption.

Table 5 lists the assumptions for the most important factors in the lower and upper bounds of potential CAV energy impacts. The most important factors are different for the lower bound than for the upper bound, since different assumptions lead to the two bounds. 
Table 5. Assumptions about the Important Factors Influencing Lower and Upper Bounds of the Potential Energy Impacts of Advanced CAV Technologies

\begin{tabular}{ll}
\hline Lower Energy Bound & Upper Energy Bound \\
\hline Low travel demand impact & $\begin{array}{l}\text { High travel demand impact } \\
\text { (easier travel and underserved) }\end{array}$ \\
Vehicle/powertrain resizing & Faster travel \\
Driving/traffic smoothing & Empty miles traveled \\
Ridesharing & \\
\hline
\end{tabular}

In order to show the relative importance of the various factors, the bounds on total fuel use by the entire U.S. LDV on-road fleet (plotted in Figures ES-2 and 5) were disaggregated for the "Full-With Rideshare" scenario. To show the influence of changes in demand (VMT) by factor, the increment in fuel used due to each demand factor was calculated by multiplying the baseline fuel consumed per mile by the VMT increment (either positive or negative). Changes in city and highway VMT were calculated separately as described in Section 3.1.1, and the appropriate city or highway fuel economy was used to estimate the fuel use corresponding to each demand increment.

These increments in demand for the "Full-With Rideshare-UB" case are shown in the upper portion of Figure 10, with the direction of the change in demand shown by the arrows. The largest increment is due to easier travel, followed by underserved. Other effects give modest VMT changes for this upper bound case. The lower portion of Figure 10 shows the estimated changes in fuel consumption due to each CAV factor that influences vehicle efficiency. These increments are calculated by taking the upper bound of VMT (including all demand effects for the upper bound), and calculating total fuel use resulting from the influence of each efficiency factor. For this upper bound case, drive smoothing and faster travel are both larger than other efficiency factors, but are of opposite signs and nearly cancel each other out. Taking all factors into account gives the upper bound on fuel use for this scenario: about $200 \%$ greater than the baseline level (i.e., leading to a potential tripling of present LDV fuel use). 


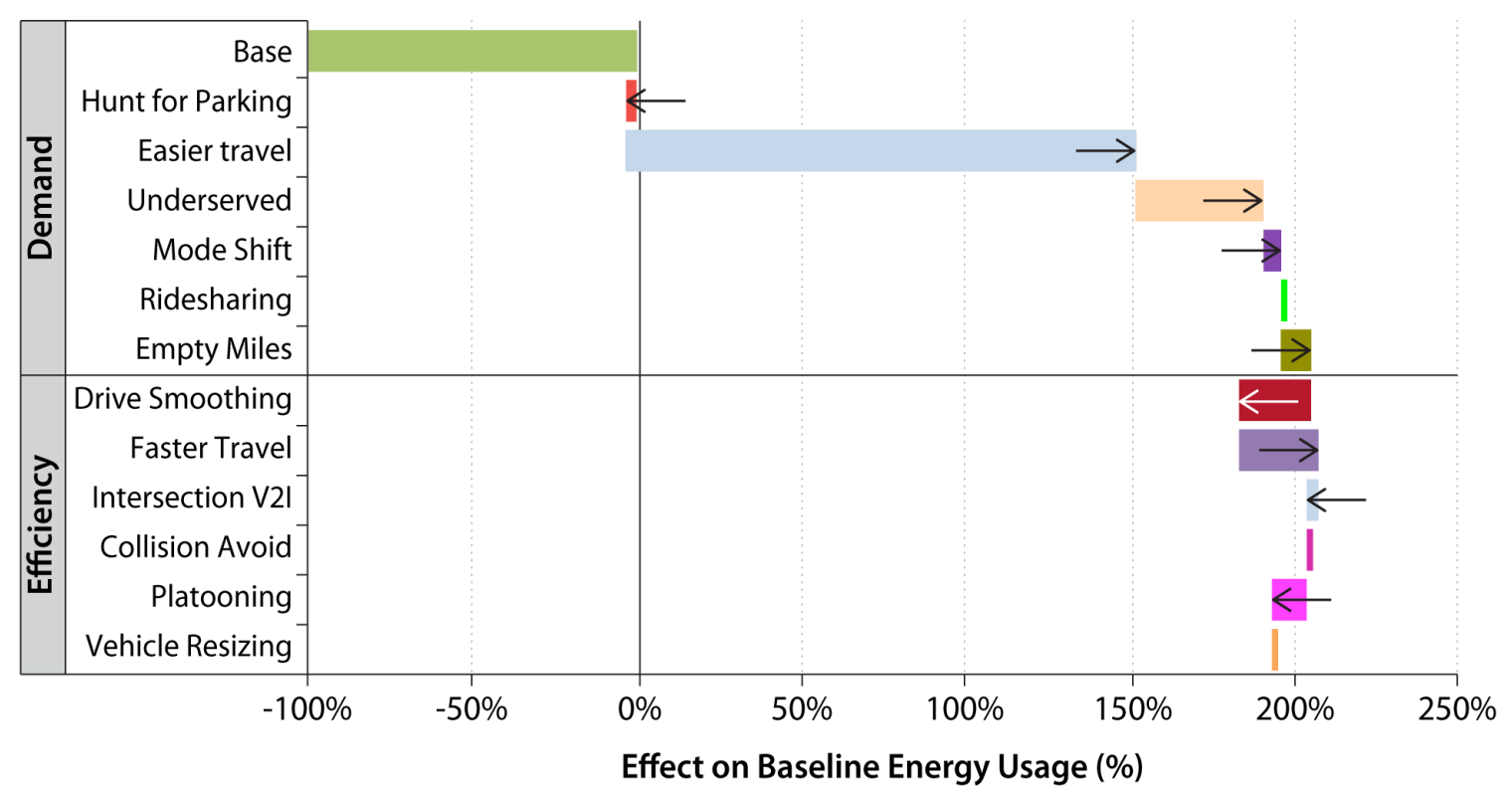

Figure 10. Influence of each demand and vehicle efficiency effect on total fuel use, for the "FullWith Rideshare-UB" case shown as percentages of total baseline fuel use

The same procedure is used to disaggregate the total fuel use for the "Full-With Rideshare-LB." case, and this is shown in Figure 11 (though note the change in the scale of the horizontal axis). In the lower bound case, easier travel is still the largest contributor to increased demand, but ridesharing and less hunting for parking serve to decrease demand, resulting in very little net change in fuel consumption due to VMT changes. Continuing from the net VMT calculation and applying each vehicle efficiency effect in turn gives the increments due to changes in vehicle efficiency, shown in the lower portion of Figure 11. The largest factor is vehicle resizing, followed by drive cycle smoothing. Taking all factors into account gives the lower bound on fuel use of less than $40 \%$ of the baseline level (more than a $60 \%$ reduction). 


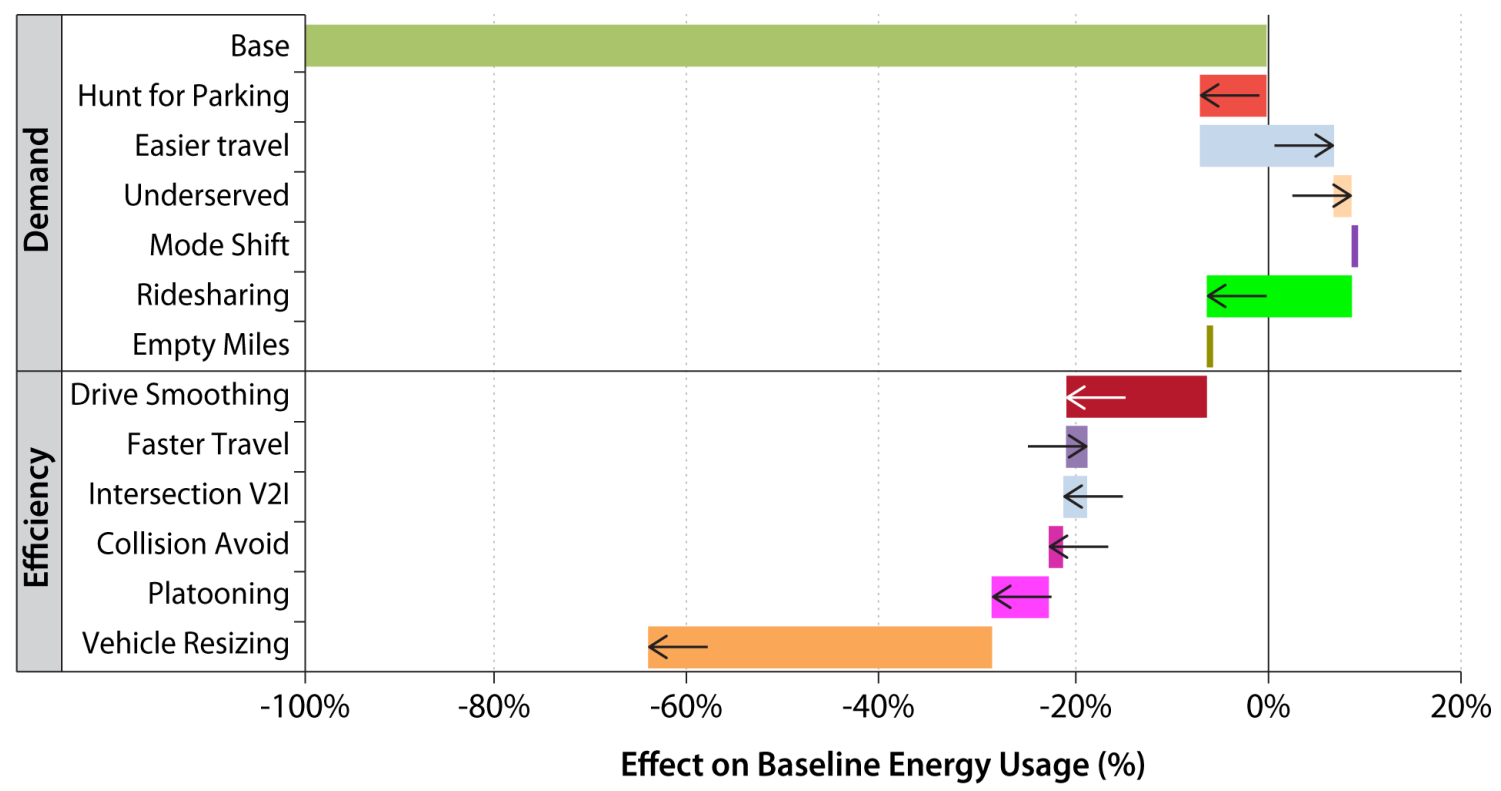

Figure 11. Influence of each demand and vehicle efficiency effect on total fuel use, for the "FullWith Rideshare-LB" case shown as percentages of total baseline fuel use

It should be noted that these are bounds and not predictions of future outcomes. The large differences between the upper and lower bounds for the most influential factors shows the large uncertainty in the potential impacts of CAVs on travel demand and vehicle fuel efficiency. These uncertainties and key knowledge gaps are discussed in Section 4.2.

\subsection{Important Uncertainties, Knowledge Gaps, and Limitations of Current Methods}

As is apparent from the review of literature and the synthesis of findings on potential energy impacts of CAVs, there is enormous uncertainty in many important factors. Based on current understanding and available information, the gaps in data and knowledge of CAV energy impacts are organized into general categories:

- Travel demand impact

- CAV adoption

- Vehicle fuel efficiency

- Vehicle redesign

- Heavy-duty CAVs.

The first four deal with passenger travel in light-duty CAVs, while the last addresses heavy-duty CAVs. For each of these categories, Tables 6 through 10 list the key questions, data gaps, and possible approaches to addressing these questions. 
Table 6. Key Uncertainties in Estimating the Potential Impacts of Advanced CAV Technologies on Travel Demand

\begin{tabular}{|c|c|c|}
\hline Specific Questions & Data Gaps & Possible Methodologies \\
\hline $\begin{array}{l}\text { How much empty } \\
\text { vehicle travel will be } \\
\text { due to CAVs? }\end{array}$ & $\begin{array}{l}\text { Changes in trip frequency, } \\
\text { distance distribution, } \\
\text { occupancy (including } \\
\text { empty CAVs) by } \\
\text { demographic groups }\end{array}$ & $\begin{array}{l}\text { Activity-based simulations can provide estimates for metropolitan areas, depending on } \\
\text { assumptions about costs of fully automated vehicles vs. conventional vehicles. Vehicle } \\
\text { travel will depend on household activities and demographics. }\end{array}$ \\
\hline $\begin{array}{l}\text { How much induced } \\
\text { demand will there be } \\
\text { from normal and } \\
\text { underserved } \\
\text { populations? }\end{array}$ & $\begin{array}{l}\text { Changes in trip frequency, } \\
\text { distance distribution, } \\
\text { occupancy (including } \\
\text { empty CAVs) by } \\
\text { demographic groups }\end{array}$ & $\begin{array}{l}\text { Estimates of underserved populations are available but somewhat uncertain. Projections } \\
\text { of future underserved populations are more uncertain. Estimates of change in travel } \\
\text { demand of an underserved individual (not necessarily the same as a regular driver) may } \\
\text { be available, but are highly uncertain. }\end{array}$ \\
\hline $\begin{array}{l}\text { How much demand } \\
\text { change will be due } \\
\text { to ride sharing? }\end{array}$ & $\begin{array}{l}\text { Changes in vehicle } \\
\text { occupancy }\end{array}$ & $\begin{array}{l}\text { Some literature estimates are available, but are uncertain. Activity-based simulations can } \\
\text { provide estimates for metropolitan areas, but future ridesharing behaviors are uncertain. }\end{array}$ \\
\hline $\begin{array}{l}\text { How much will } \\
\text { demand change } \\
\text { from mode shift } \\
\text { between CAVs and } \\
\text { public transit? }\end{array}$ & $\begin{array}{l}\text { Changes in mode shares } \\
\text { (car vs. transit) }\end{array}$ & $\begin{array}{l}\text { Activity-based simulations can provide estimates for metropolitan areas. Regional, long- } \\
\text { distance travel models can provide estimates. Potential impacts are large. }\end{array}$ \\
\hline $\begin{array}{l}\text { How might land use } \\
\text { change with high } \\
\text { levels of automation } \\
\text { / connectivity? }\end{array}$ & $\begin{array}{l}\text { How will trip patterns } \\
\text { (frequency, distance } \\
\text { distribution) change? }\end{array}$ & $\begin{array}{l}\text { Current land use change models would need to be extended to include potential } \\
\text { influences of CAVs. }\end{array}$ \\
\hline
\end{tabular}


Table 7. Key Uncertainties in Estimating the Potential Adoption Levels of Advanced CAV Technologies

\begin{tabular}{|c|c|c|}
\hline Specific Questions & Data Gaps & Possible Methodologies \\
\hline $\begin{array}{l}\text { How will travel time } \\
\text { cost change with } \\
\text { CAVs (considering } \\
\text { stress reduction, } \\
\text { increased } \\
\text { productivity)? }\end{array}$ & $\begin{array}{l}\text { Difference in utility of } \\
\text { travelers in CAV vs. non- } \\
\text { CAV (distributions), } \\
\text { including value of } \\
\text { increased safety } \\
\text { perceived by users in } \\
\text { vehicles with various } \\
\text { connectivity and } \\
\text { automation capabilities }\end{array}$ & $\begin{array}{l}\text { Some components of value may be difficult to quantify. An existing model (MA3T) can be } \\
\text { generalized for projecting adoption of connected and automated light-duty passenger } \\
\text { vehicles. A different approach may be needed for commercial or shared vehicles. Three } \\
\text { approaches are possible: } \\
\text { - Survey-based estimates relying on stated (if not revealed) preferences } \\
\text { - Direct estimates based on network simulation } \\
\text { - Analogy estimates based on literature on cost-benefit studies of transit and taxi } \\
\text { consumers. } \\
\text { The need for data is high, and potential impacts are large. }\end{array}$ \\
\hline $\begin{array}{l}\text { What will be the } \\
\text { incremental } \\
\text { purchase prices of } \\
\text { CAVs? }\end{array}$ & $\begin{array}{l}\text { CAV costs, considering } \\
\text { possible vehicle } \\
\text { capabilities, technologies, } \\
\text { and vehicle resizing } \\
\text { scenarios }\end{array}$ & $\begin{array}{l}\text { CAV technology costs and projections have been collected from literature. Future costs } \\
\text { are uncertain. Cost reduction and tipping point history of certain former luxury features } \\
\text { may be used to estimate future costs. CAV configurations for different consumer } \\
\text { segments may be diverse, creating a modeling challenge. }\end{array}$ \\
\hline $\begin{array}{l}\text { How will ownership } \\
\text { costs of CAVs differ } \\
\text { from those of } \\
\text { conventional } \\
\text { vehicles? }\end{array}$ & $\begin{array}{l}\text { Fuel cost per mile, } \\
\text { insurance costs, } \\
\text { maintenance costs, and } \\
\text { other costs }\end{array}$ & $\begin{array}{l}\text { Fuel cost per mile can be estimated from analysis results. Literature is widely available } \\
\text { on estimates of different ownership cost components for conventional vehicles. Analogies } \\
\text { can be made to examine how CAVs can reduce certain cost components, and changes in } \\
\text { crash-related costs (insurance, repair etc.) can be estimated based on projected changes } \\
\text { in crash frequencies. }\end{array}$ \\
\hline $\begin{array}{l}\text { What is the } \\
\text { willingness to pay for } \\
\text { CAVs within different } \\
\text { market segments? }\end{array}$ & $\begin{array}{l}\text { Consumer segment sizes } \\
\text { based on disability, age, } \\
\text { income, and other relevant } \\
\text { demographic attributes }\end{array}$ & $\begin{array}{l}\text { Willingness to pay by different market segments can be estimated at least roughly from } \\
\text { surveys and willingness to pay for analogous products and services. An optimization } \\
\text { approach can provide results to compare with survey-based results. }\end{array}$ \\
\hline
\end{tabular}


Table 8. Key Uncertainties in Estimating the Potential Impacts of Advanced CAV Technologies on Vehicle Fuel Efficiency

\begin{tabular}{|c|c|c|}
\hline Specific Questions & Data Gaps & Possible Methodologies \\
\hline $\begin{array}{l}\text { How will fuel } \\
\text { consumption by } \\
\text { CAVs differ from } \\
\text { conventional } \\
\text { vehicles? }\end{array}$ & $\begin{array}{l}\text { Distributions of fuel } \\
\text { consumption per mile per } \\
\text { vehicle for urban, } \\
\text { suburban, and rural areas } \\
\text { by roadway type, } \\
\text { congestion level, drivetrain }\end{array}$ & $\begin{array}{l}\text { Of the uncertainties discussed, this is the one most covered by literature, so existing } \\
\text { studies can at least serve as a fallback. High-fidelity vehicle simulation tools are available } \\
\text { and have been run for conventional internal combustion engine vehicles (which will serve } \\
\text { as baseline) and can be used to simulate connected and automated internal combustion } \\
\text { engine vehicles under appropriate driving conditions. Simulation results will be needed } \\
\text { for many analyses. Estimates based on disparate literature sources are not adequate. }\end{array}$ \\
\hline $\begin{array}{l}\text { How will CAVs } \\
\text { influence fuel } \\
\text { consumption by } \\
\text { different drivetrains? }\end{array}$ & $\begin{array}{l}\text { Distributions of fuel } \\
\text { consumption per mile per } \\
\text { vehicle for urban, } \\
\text { suburban, and rural areas } \\
\text { by roadway type, } \\
\text { congestion level, drivetrain }\end{array}$ & $\begin{array}{l}\text { High-fidelity vehicle simulation tools are available and have been run for vehicles of } \\
\text { multiple drivetrain types (which will serve as baseline) and will be used to simulate } \\
\text { connected and automated alternative drivetrain vehicles under appropriate driving } \\
\text { conditions. These will be needed for many analyses; however, little work on energy } \\
\text { consumption by connected/automated alternative drivetrains has been reported, so the } \\
\text { need for data is high. Potential impacts are significant, but not as large as other factors. }\end{array}$ \\
\hline $\begin{array}{l}\text { How will efficiency } \\
\text { impacts from } \\
\text { multiple CAV } \\
\text { features interact } \\
\text { when implemented } \\
\text { simultaneously? }\end{array}$ & $\begin{array}{l}\text { Distributions of fuel } \\
\text { consumption per mile per } \\
\text { vehicle for different } \\
\text { combinations of CAV } \\
\text { features over urban, } \\
\text { suburban, and rural areas } \\
\text { by roadway type, } \\
\text { congestion level, drivetrain }\end{array}$ & $\begin{array}{l}\text { Existing literature tends to assess the fuel savings benefits from individual CAV energy } \\
\text { efficiency features, rather than multiple combinations. As such, analyses to date } \\
\text { estimating the cumulative potential impact from implementing multiple features } \\
\text { simultaneously have been forced to speculate on the possibility of isolated individual } \\
\text { benefits being additive when combined. Moderately high priority should be placed on } \\
\text { expanded field testing of prototype CAV deployments using several efficiency } \\
\text { technologies concurrently, along with exercising well-validated models of multi-feature } \\
\text { CAVs over a large range of operating conditions. }\end{array}$ \\
\hline $\begin{array}{l}\text { How do the } \\
\text { interactions between } \\
\text { CAVs and non-CAVs } \\
\text { influence driving and } \\
\text { fuel consumption? }\end{array}$ & $\begin{array}{l}\text { Energy impact of CAVs } \\
\text { compared with non-CAVs, } \\
\text { driving in fleets with } \\
\text { different CAV technology } \\
\text { penetration levels }\end{array}$ & $\begin{array}{l}\text { Transportation system simulation tools can be used if driving behavior is appropriately } \\
\text { modeled. This will be needed to estimate changes in vehicle energy consumption in } \\
\text { mixed (CAV and non-CAV) traffic in both city and highway driving, which will be the case } \\
\text { in most scenarios analyzed. Potential impacts are moderate to large (and could include } \\
\text { secondary impacts on non-CAVs due to CAV influences on the overall traffic flow). }\end{array}$ \\
\hline $\begin{array}{l}\text { What is the influence } \\
\text { of traffic congestion } \\
\text { on CAVs' energy } \\
\text { impact? }\end{array}$ & $\begin{array}{l}\text { Energy impact of CAVs } \\
\text { compared with non-CAVs, } \\
\text { driving on different } \\
\text { congestion level roads } \\
\text { (the congestion level can } \\
\text { be quantified as level of } \\
\text { service, or actual } \\
\text { speed/free flow speed } \\
\text { ratio, etc.) }\end{array}$ & $\begin{array}{l}\text { High-fidelity vehicle simulation tools along with data when available will be used to } \\
\text { analyze connected and automated alternative drivetrain vehicle operation under a range } \\
\text { of driving conditions. Congested driving can be simulated using global positioning system } \\
\text { data and activity-based transportation system modeling or modeling of specific roadway } \\
\text { types/intersections. These results will be needed for many analyses. Methods are being } \\
\text { developed and refined to account for congestion in the national-level roll-up. }\end{array}$ \\
\hline
\end{tabular}


Table 9. Key Uncertainties in Estimating the Potential Impacts of Advanced CAV Technologies on Vehicle Redesign/Resizing

\begin{tabular}{|c|c|c|}
\hline Specific Questions & Data Gaps & Possible Methodologies \\
\hline $\begin{array}{l}\text { Do we need to } \\
\text { consider consumer } \\
\text { acceptance on } \\
\text { vehicle resizing? }\end{array}$ & $\begin{array}{l}\text { Differences in passenger } \\
\text { utility or preferences for } \\
\text { vehicle attributes between } \\
\text { fully automated CAVs }\end{array}$ & $\begin{array}{l}\text { Potential impact of resizing can be very large, but resizing estimates will also be } \\
\text { extremely uncertain and speculative. Analyses should highlight the general direction of } \\
\text { the impacts under different scenarios, but should probably avoid overly precise } \\
\text { quantification statements. A scenario dividing line should also be established between }\end{array}$ \\
\hline $\begin{array}{l}\text { What is the most } \\
\text { appropriate resize } \\
\text { scale under a fully } \\
\text { automated/ } \\
\text { connected vehicle } \\
\text { scenario? }\end{array}$ & $\begin{array}{l}\text { compared with } \\
\text { conventional or different } \\
\text { powertrain vehicles, and } \\
\text { resulting changes in fuel } \\
\text { economy }\end{array}$ & $\begin{array}{l}\text { mixed driving of CAVs and non-CAVs on the road (likely to be the case for a long time } \\
\text { into the future) vs. exclusive operation of CAVs on the roadway with no mixed traffic. }\end{array}$ \\
\hline $\begin{array}{l}\text { How might vehicle } \\
\text { design change with } \\
\text { CAV-enabled car } \\
\text { sharing? }\end{array}$ & $\begin{array}{l}\text { Changes in passenger } \\
\text { utility or preferences for } \\
\text { vehicle attributes in } \\
\text { shared vs. privately owned } \\
\text { vehicles, and resulting fuel } \\
\text { economy changes }\end{array}$ & $\begin{array}{l}\text { Scenarios based on exogenous assumptions can be analyzed initially, with refinements } \\
\text { as additional behavioral data and improved modeling capabilities permit. }\end{array}$ \\
\hline $\begin{array}{l}\text { How might vehicle } \\
\text { design change with } \\
\text { CAVs or increased } \\
\text { ride sharing? }\end{array}$ & $\begin{array}{l}\text { Changes in passenger } \\
\text { utility or preferences for } \\
\text { vehicle attributes in } \\
\text { shared vehicles used by } \\
\text { multiple passengers at } \\
\text { once (ridesharing), and } \\
\text { resulting fuel economy } \\
\text { changes }\end{array}$ & $\begin{array}{l}\text { A similar scenario approach can be used, with assumptions about ridesharing } \\
\text { preferences, with more in-depth analysis as improved data and modeling permit. }\end{array}$ \\
\hline $\begin{array}{l}\text { How might vehicle } \\
\text { design change } \\
\text { without having a } \\
\text { driver? }\end{array}$ & $\begin{array}{l}\text { Consumer willingness to } \\
\text { change from conventional } \\
\text { vehicle layout, knowledge } \\
\text { of how passengers would } \\
\text { want to use their time }\end{array}$ & $\begin{array}{l}\text { While this study assumed that vehicle redesign would improve fuel economy due to } \\
\text { lightweighting of vehicles, it remains to be seen if vehicle weight will increase due to } \\
\text { increased amenities. Survey data and other behavioral studies could be examined to see } \\
\text { how people would use their vehicles if fully automated. }\end{array}$ \\
\hline
\end{tabular}


Table 10. Key Uncertainties in Estimating the Potential Energy Impacts of Heavy-Duty CAV Technologies

\begin{tabular}{|c|c|c|}
\hline Specific Questions & Data Gaps & Possible Methodologies \\
\hline $\begin{array}{l}\text { What driver } \\
\text { assistance/ } \\
\text { connectivity } \\
\text { technologies (other } \\
\text { than platooning) } \\
\text { might be adopted } \\
\text { and to what extent? }\end{array}$ & $\begin{array}{l}\text { VMT in partially } \\
\text { automated/connected } \\
\text { trucks, changes in fuel } \\
\text { consumption with driver } \\
\text { assistance }\end{array}$ & $\begin{array}{l}\text { Outputs from platooning studies and related literature can address this gap in the near } \\
\text { term, to be supplemented in the long term with truck-specific analyses beyond platooning } \\
\text { (e.g., traffic signal coordination) for incorporation into multi-transportation-sector national- } \\
\text { level analysis. }\end{array}$ \\
\hline $\begin{array}{l}\text { What is the fraction } \\
\text { of heavy truck VMT } \\
\text { available for truck } \\
\text { platooning? }\end{array}$ & $\begin{array}{l}\text { VMT in platoons, changes } \\
\text { in fuel consumption with } \\
\text { driver assistance, fraction } \\
\text { of VMT truck drivers would } \\
\text { be willing to travel in } \\
\text { platoons }\end{array}$ & $\begin{array}{l}\text { Gaps can be filled with freight-flow analysis, and then applied to heavy truck and } \\
\text { passenger vehicle aggregation. }\end{array}$ \\
\hline $\begin{array}{l}\text { What are energy } \\
\text { benefits of } \\
\text { platooning? }\end{array}$ & $\begin{array}{l}\text { Aerodynamic drag } \\
\text { simulations across vehicle } \\
\text { designs, on-road } \\
\text { platooning data }\end{array}$ & $\begin{array}{l}\text { Ongoing studies of platooning give bounds of energy benefits, but these bounds can be } \\
\text { refined with additional simulations and on-road data. Tractor and trailer design also play } \\
\text { a role in quantifying and optimizing the benefits of platooning. }\end{array}$ \\
\hline $\begin{array}{l}\text { How might freight } \\
\text { traffic be changed by } \\
\text { high degrees of } \\
\text { automation and } \\
\text { changes in public } \\
\text { behavior? }\end{array}$ & $\begin{array}{l}\text { Public acceptance and } \\
\text { behavioral studies, multi- } \\
\text { modal shipping data, land- } \\
\text { use projections }\end{array}$ & $\begin{array}{l}\text { Public acceptance of a large-scale automated vehicle fleet needs to be studied to } \\
\text { determine the uptake of heavy-duty CAVs. If acceptance is high, there can be major } \\
\text { impacts on the shipping industry, with changes in how goods are shipped. For example, } \\
\text { will there be an increase in medium-duty truck use for deliveries, such as from personal } \\
\text { goods shipments? Surveys to determine readiness and development of transportation } \\
\text { system models will be necessary to determine the demand for heavy-duty CAVs. }\end{array}$ \\
\hline
\end{tabular}




\section{Conclusions and Recommendations}

Based on a review of literature and synthesis of findings on possible CAVs' energy implications, there is enormous uncertainty in potential long-term energy impacts if fully automated and highly connected vehicles replace nearly all light-duty passenger vehicles in the United States. Scenarios representing lower and upper bounds of changes in fuel use for a national fleet of conventional powertrain vehicles were assessed with projected energy use reaching as low as less than $40 \%$ and as high as three times the current level of U.S. LDV fuel consumption.

The wide range between the lower and upper bounds on future vehicle energy use reflects the large uncertainties in ways that CAVs can potentially influence vehicle efficiency and use through changes in vehicle design, driving, and travel behavior. In addition, significant uncertainty exists regarding future CAV technology adoption rates. Use of alternative powertrain technologies such as vehicle electrification will be expected to reduce both the upper and lower bounds on fuel consumption for the examined scenarios. However, the relative impact of different CAV features in advanced powertrains is expected to be different than the corresponding impact in conventional vehicles, so future work will more rigorously explore the combined impacts of advanced powertrain and CAV technologies.

For each of the factors examined in this report, the most significant drivers of possible fuel use (and greenhouse gas emission) changes have been identified. The most important data and knowledge gaps in each of these factors have also been assessed and prioritized on the basis of their importance to estimating future energy impacts and tractability of approaches to addressing the gaps.

Research needed to address these gaps includes:

- Assessing potential changes in travel demand due to CAVs

Analyzing potential changes in travel demand, vehicle use, mode choice, etc., in large-scale simulations with CAVs and simulating traveler behaviors in appropriate contexts, such as large metropolitan areas or corridors is necessary to enable analysis of how travel behavior and vehicle use might change with CAVs under different conditions. Methods to expand the results of these simulations to the national scale will be needed, since high-fidelity nationallevel simulations will not be computationally feasible.

- Estimating future CAV adoption

The impact of CAVs will clearly depend on how many are on the road. Consumer choice models need to be extended to include choices such as whether to buy a vehicle, and whether to buy a vehicle with CAV capabilities as well as with other attributes (e.g., powertrain type). Results of projected adoption levels will be needed in travel behavior simulations and energy analyses. More data on consumer preferences for CAV features will be needed.

- Analyzing potential effects on vehicle efficiency and redesign

While a number of vehicle-level studies have provided important results on potential influences of CAV technologies on vehicle efficiency, much work remains to analyze efficiency effects under a wider range of conditions and for more powertrain types, in 
particular for a wider range of driving cycles. Because CAVs may be designed much differently from current LDVs with drastic downsizing, less crash protection, different performance characteristics, and other changes, fuel consumption needs to be analyzed for a wide range of vehicle configurations. Methods will be needed to map the vehicle-level analysis results to the entire U.S. on-road fleet under relevant conditions.

- Estimating future heavy-duty CAV energy impacts

For a range of CAV capabilities, potential adoption levels and impacts on operation and the resulting fuel use need to be assessed. In particular, more work is needed to estimate the fraction of VMT that could be driven by long-haul freight trucks in platoons and the potential energy savings.

A large effort is required to address these questions, but the potential energy impacts are very large, which makes this research a high priority. It is also important that this research be integrated with broader research on traveler behavior, simulation and modeling methods, and collection of transportation and vehicle data. This report identifies the most significant potential impacts, the largest areas of uncertainty, and where further research is particularly needed. 


\section{References}

Anderson, J.M., N. Kalra, K.D. Stanley, P. Sorensen, C. Samaras, and O. Oluwatola. Autonomous Vehicle Technology: A Guide for Policymakers. Santa Monica, CA: RAND Corporation, 2016. http://www.rand.org/pubs/research reports/RR443-2.html. Also available in print form.

Barth, M. 2013. "Preliminary Eco-Approach and Departure at Signalized Intersections Modeling Results." Accessed November 7, 2016. http://www.its.dot.gov/research_archives/aeris/pdf/UCR_eco-approach_final2.pdf.

Barth, M., and K. Boriboonsomsin. 2008. "Real-World $\mathrm{CO}_{2}$ Impact of Traffic Congestion." Transportation Research Record: Journal of the Transportation Research Board, no. 2058. Transportation Research Board of the National Academies, Washington, D.C. 163-171.

Barth, M., and K. Boriboonsomsin. 2009. "Energy and Emissions Impacts of a Freeway-Based Dynamic Eco-Driving System." Transportation Research Part D: Transport and Environment, The Interaction of Environmental and Traffic Safety Policies 14:400-410. doi:10.1016/j.trd.2009.01.004.

Berry, I.M. 2010. "The Effects of Driving Style and Vehicle Performance on the Real-World Fuel Consumption of US Light-Duty Vehicles." Master's thesis, Massachusetts Institute of Technology.

Bertoncello, Michele, and Dominik Wee. 2015. "Ten Ways Autonomous Driving Could Redefine the Automotive World.” Accessed November 7, 2016.

http://www.mckinsey.com/industries/automotive-and-assembly/our-insights/ten-waysautonomous-driving-could-redefine-the-automotive-world.

Boston Consulting Group. 2015a. "Revolution in the Driver's Seat: The Road to Autonomous Vehicles." Accessed November 7, https://www.bcgperspectives.com/Images/BCG-Revolutionin-the-Drivers-Seat-Apr-2015 tcm80-186097.pdf.

Boston Consulting Group. 2015b. "A Roadmap to Safer Driving Through Advanced Driver Assistance Systems." Accessed November 7, https://www.bcgperspectives.com/Images/MEMABCG-A-Roadmap-to-Safer-Driving-Sep-2015.pdf.

Brown, A., J. Gonder, and B, Repac. 2014. "An Analysis of Possible Energy Impacts of Automated Vehicles." In Road Vehicle Automation, edited by G. Meyer and S. Beiker. 137-153. Switzerland: Springer International Publishing. DOI:10.1007/978-3-319-05990-7_13.

Bureau of Transportation Statistics. 2003. Freedom to Travel. Publication \#BTS03-08. U.S. Department of Transportation Research and Innovative Technology Administration. Accessed November 7, 2016. http://www.rita.dot.gov/bts/sites/rita.dot.gov.bts/files/publications/freedom to travel/index.html. 
Bureau of Transportation Statistics. n.d., TranStats Data Library, in the Database "Air Carrier Statistics (Form 41 Traffic) - All Carriers."

http://www.transtats.bts.gov/databases.asp?pn=1\&Mode ID=1\&Mode Desc=Aviation\&Subject ID2 $=0$, Table "T-100 Domestic Segments (All Carriers)."

Burns, Lawrence D., William C. Jordan, and Bonnie A. Scarborough. 2013. Transforming Personal Mobility. The Earth Institute, Columbia University. Accessed November 7, 2016. http://sustainablemobility.ei.columbia.edu/files/2012/12/Transforming-Personal-Mobility-Jan27-20132.pdf.

Cervero, Robert. 2001. "Induced Demand: An Urban and Metropolitan Perspective." Prepared for Policy Forum: Working Together to Address Induced Demand. Berkeley, CA.

Childress, S., B. Nichols, B. Charlton, and S. Coe. 2015. "Using an Activity-Based Model to Explore Possible Impacts of Automated Vehicles." Presented at Transportation Research Board 2015 Annual Meeting, TRB 94th Annual Meeting Compendium of Papers, no. 15-5118, Transportation Research Board, Washington, DC.

Edmunds. "2015 Honda Accord True Cost to Own.” Accessed November 21, 2016. http://www.edmunds.com/honda/accord/2015/st-200709379/cost-to-own/?zip=37830.

EIA (Energy Information Agency), 2014, Annual Energy Outlook 2014: With Projections to 2040, DOE/EIA-0383(2013), Office of Integrated Analysis and Forecasting, Energy Information Administration, U.S. Department of Energy, Washington, D.C.

Fagnant, D.J., and K.M. Kockelman. 2014. "The Travel and Environmental Implications of Shared Autonomous Vehicles, Using Agent-Based Model Scenarios." Transportation Research Part C: Emerging Technologies 40:1-13.

Fagnant, D.J., and K. Kockelman. 2015a. "Preparing a Nation for Autonomous Vehicles: Opportunities, Barriers and Policy Recommendations." Transportation Research Part A: Policy and Practice 77:167-181.

Fagnant, D.J., and K.M. Kockelman. 2015b. "Dynamic Ride-Sharing and Optimal Fleet Sizing for a System of Shared Autonomous Vehicles." Presented at Transportation Research Board 2015 Annual Meeting, TRB 94th Annual Meeting Compendium of Papers, no. 15-1962, Transportation Research Board, Washington, DC.

Federal Highway Administration. (FHWA. 2011) "Summary of Travel Trends: 2009 National Household Travel Survey,” report number FHWA-PL-11-022, June, 2011.

http://nhts.ornl.gov/publications.shtml. Accessed November 21, 2016.

Federal Transit Administration (FTA), n.d., "The National Transit Database (NTD)." Updated June 8, 2016. https://www.transit.dot.gov/ntd.

Greenblatt, J.B., and S. Saxena. 2015. "Autonomous Taxis Could Greatly Reduce GreenhouseGas Emissions of US Light-Duty Vehicles.” Nature Climate Change 2685.

doi:10.1038/nclimate2685. 
Gucwa, M. 2014. "Mobility and Energy Impacts of Automated Cars." Presentation to the Automated Vehicles Symposium, Burlingame, CA, July 16.

Harper, C., S. Mangones, C.T. Hendrickson, and C. Samaras. 2015. "Bounding the Potential Increases in Vehicles Miles Traveled for the Non-Driving and Elderly Populations and People with Travel-Restrictive Medical Conditions in an Automated Vehicle Environment." Presented at Transportation Research Board 2015 Annual Meeting, Washington, DC. TRB 94th Annual Meeting Compendium of Papers, no. 15-1609.

Hymel, K.M., K.A. Small, and K. Van Dender. 2010. "Induced Demand and Rebound Effects in Road Transport." Transportation Research Part B: Methodological 44:1220-1241.

IHS Automotive. 2014. Emerging Technologies: Autonomous Cars-Not If, But When. Accessed November 7, 2016. http://press.ihs.com/press-release/automotive/self-driving-cars-movingindustrys-drivers-seat.

Kasseris, E.P. 2006. "Comparative Analysis of Automotive Powertrain Choices for the Near to Mid-term Future.” Master's Thesis, Massachusetts Institute of Technology. https://dspace.mit.edu/handle/1721.1/36239.

KPMG. 2015a. "The Clockspeed Dilemma: What Does It Mean for Automotive Innovation?" Accessed November 7, 2016. https://home.kpmg.com/xx/en/home/insights/2015/12/theclockspeed-dilemma-gary-silberg-head-of-automotive-kpmg-us.html.

KPMG. 2015b. "Marketplace of Change: Automobile Insurance in the Era of Autonomous Vehicles." Accessed November 7, 2016. https://home.kpmg.com/content/dam/kpmg/pdf/2016/05/marketplace-change.pdf.

Li, J. and Z. Gao. 2013. "Exploring the Impact of Speed Synchronization through Connected Vehicle Technology on Fleet-Level Fuel Economy." SAE Int. J. Passeng. Cars - Electron. Electr. Syst. 6:2013.

Light, D. 2012. “A Scenario: The End of Auto Insurance.” Accessed November 7, 2016. http://celent.com/reports/scenario-end-auto-insurance?WT.qs_osrc=nas-122850910.

Litman, T. 2015. Autonomous Vehicle Implementation Predictions: Implications for Transport Planning. Victoria Transport Policy Institute. 22 pp. Accessed November 7, 2016. http://www.vtpi.org/avip.pdf.

MacKenzie D., Z. Wadud, and P. Leiby. 2014. "A First Order Estimate of Energy Impacts of Automated Vehicles in the United States." Presented at Transportation Research Board 2014 Annual Meeting, Washington, DC. TRB 93rd Annual Meeting Compendium of Papers, no. 142193.

Michel, P., D. Karbowski, and A. Rousseau. 2016. "Impact of Connectivity and Automation on Vehicle Energy Use.” SAE Technical Paper 2016-01-0152.

https://saemobilus.sae.org/content/2016-01-0152. 
Moore M., and D. Zuby. 2013. "Collision Avoidance Features: Initial Results." 23rd International Conference on the Enhanced Safety of Vehicles. Accessed November 7, 2016. http://trid.trb.org/view.aspx?id=1359984.

Najm W.G., M.D. Stearns. H. Howarth, J. Koopman, and J. Hitz. 2006. Evaluation of an Automotive Rear End Collision Avoidance System. U.S. Department of Transportation. Report no. DOT-VNTSC-NHTSA-06-01. Accessed November 7, 2016, http://www.nhtsa.gov/DOT/NHTSA/NRD/Multimedia/PDFs/Crash\%20Avoidance/2006/HS910 $\underline{569 . p d f}$.

National Association of Insurance Commissioners. 2015. "Auto Insurance Database Report 2012/2013." Accessed November 7, 2016.

http://www.naic.org/documents/prod_serv_statistical_aut_pb.pdf.

National Transportation Safety Board (NTSB). 2015. "The Use of Forward Collision Avoidance Systems to Prevent and Mitigate Rear-End Crashes," report NTSB/SIR-15/01 PB2015-104098, May. Accessed November 21, 2016.

http:/www.google.com/url?sa=t\&rct=j\&q=\&esrc=s\&source=web\&cd=8\&cad=rja\&uact $=8 \& v e d$ $=0$ ahUKEwjaj8f61brQAhWSZiYKHbo1BU4QFghIMAc\&url=http $\% 3 \mathrm{~A} \% 2 \mathrm{~F} \% 2 \mathrm{Fwww} . \mathrm{ntsb}$.gov \%2Fsafety\%2Fsafety-studies\%2FDocuments\%2FSIR1501.pdf\&usg=AFQjCNHO6yF9vcLfuRpYUCkA14hDrqRbg\&bvm=bv.139250283,d.eWE.

Porter, C.D., A. Brown, J. DeFlorio, E. McKenzie, W. Tao, and L. Vimmerstedt. 2013. Effects of Travel Reduction and Efficient Driving on Transportation: Energy Use and Greenhouse Gas Emissions. Transportation Energy Futures Series. Prepared by the National Renewable Energy Laboratory (Golden, CO) and Cambridge Systematics, Inc. for the U.S. Department of Energy, Washington, DC. DOE/GO-102013-3704. 98 pp. http://www.nrel.gov/docs/fy13osti/55635.pdf. Accessed September 6, 2016.

Rakha, H.A., K. Ahn, and S. Park. 2012. AERIS: Eco-Driving Application Development and Testing, Final Report. U.S. Department of Transportation. Report no. FHWA-JPO-12-045. Accessed November 7, 2016. http://ntl.bts.gov/lib/47000/47500/47598/Final_Package_EcoDriving-Applications_V3.pdf.

Rakha, H.A., R.K. Kamalanathsharma, and K. Ahn. 2012. AERIS : Eco-Vehicle Speed Control at Signalized Intersections Using I2V Communication, Final Report. U.S. Department of Transportation. Report no. FHWA-JPO-12-063. Accessed November 7, 2016. http://ntl.bts.gov/lib/46000/46300/46329/FHWA-JPO-12-063 FINAL PKG.pdf.

SAE International. 2016. "Taxonomy and Definitions for Terms Related to Driving Automation Systems for On-Road Motor Vehicles," Recommended Practice J3016_201609, revised September 30. Accessed November 21, 2016. http://standards.sae.org/j3016 201609/.

Santi, P., G. Resta, M. Szell, S. Sobolevsky, S.H. Strogatz, and C. Ratti. 2014. "Quantifying the Benefits of Vehicle Pooling with Shareability Networks." Proceedings of the National Academy of Sciences, 111:13290-13294. 
Schafer, A., J.B. Heywood, H.D. Jacoby, and I.A. Waitz. 2009. Transportation in a ClimateConstrained World. Cambridge, MA: MIT Press.

Schito, P., and F. Braghin. 2012. "Numerical and Experimental Investigation on Vehicles in Platoon.” SAE Int. J. Commer. Veh. 5:63-71, doi:10.4271/2012-01-0175. https://saemobilus.sae.org/content/2012-01-0175.

Scholz, T., A. Schmallowsky, and T. Wauer. 2007. "Auswirkungen eines Allgemeinen Tempolimits auf Autobahnen im Land Brandenburg." Schlothauer \& Wauer.

Schrank, D., B. Eisele, and T. Lomax. 2012. Urban Mobility Report, Powered by INRIX Traffic Data. Texas Transportation Institute, College Station, TX.

Shoup, D.C. 2006. “Cruising for Parking,” Transport Policy 13:479-486.

Stephens, T.S., A.K. Birky, and J. Ward. 2016. Vehicle Technologies and Fuel Cell Technologies Program: Prospective Benefits Assessment Report for Fiscal Year 2016. Report no. ANL/ESD16/2. Argonne, IL: Argonne National Laboratory. DOI:10.2172/1250457. Accessed November 7, 2016. http://www.osti.gov/scitech/biblio/1250457-vehicle-technologies-fuel-cell-technologiesprogram-prospective-benefits-assessment-report-fiscal-year.

Thomas, J., Ho-Ling Hwang, B. West, and S. Huff. 2013. "Predicting Light-Duty Vehicle Fuel Economy as a Function of Highway Speed." SAE Int. J. Passeng. Cars-Mech. Syst. 6:859-875. doi:10.4271/2013-01-1113. Accessed November 7, 2016. http://papers.sae.org/2013-01-1113/.

Toups, D. 2011. "How Many Times Will You Crash Your Car?” Forbes. Accessed November 7, 2016. http://www.forbes.com/sites/moneybuilder/2011/07/27/how-many-times-will-you-crashyour-car/\#b218b1150f99.

U.S. Energy Information Agency (EIA). 2014. Annual Energy Outlook 2014: With Projections to 2040. DOE/EIA-0383(2013), Office of Integrated Analysis and Forecasting, Energy Information Administration, U.S. Department of Energy, Washington, D.C. http://www.eia.gov/forecasts/aeo/pdf/0383\%282014\%29.pdf.

U.S. Environmental Protection Agency. 2010. Motor Vehicle Emission Simulator (MOVES) 2010, User Guide. Office of Transportation and Air Quality, U.S. Environmental Protection Agency. Report no. EPA-420-B-09-041. https://nnsa.energy.gov/sites/default/files/nv sweis/appendixD/EPA\%202009.pdf.

Vincent, James. 2016. “Comma.ai Says It'll Make Your Car Semi-Autonomous for \$24 a Month." The Verge. (online). Accessed November 7, 2016. http://www.theverge.com/2016/9/14/12912668/comma-ai-george-hotz-self-driving-car-price.

Wadud, Z., D. MacKenzie, and P. Leiby. 2016. "Help or Hindrance? The Travel, Energy and Carbon Impacts of Highly Automated Vehicles." Transportation Research Part A: Policy and Practice, 86:1-18. 
Yelchuru, B., and T. Waller, 2014. Preliminary Eco-Traffic Signal Timing Modeling Results. Accessed November 7, 2016.

http://www.itsbenefits.its.dot.gov/ITS/benecost.nsf/SummID/B2014-00912.

Yelchuru, B., T. Waller, and M. Barth. 2014. Preliminary Eco-Traffic Signal Priority (for Transit and Freight Vehicles) and Connected Eco-Driving Modeling Results. Accessed November 7, 2016. http://www.its.dot.gov/research archives/aeris/pdf/EcoTrafficSignalPriority_ConnectedEco-Driving.pdf.

Zabat, M.A., N.S. Stabile, and F.K. Browand. 1995. "Estimates of Fuel Savings from Platooning." Intelligent Transportation: Serving the User Through Deployment, Proceedings of the 1995 Annual Meeting of ITS America.

Zimmerman, C., J. Marks, J. Jenq, C. Cluett, A. DeBlasio, J. Lappin, H. Rakha, and K. Wunderlich. 2000. Phoenix Metropolitan Model Deployment Initiative Evaluation Report. Report no. FHWA-OP-00-015. Federal Highway Administration, Washington, DC. 